\title{
GERAÇÃO DE DRENAGEM ÁCIDA E DE CONTAMINAÇÃO POR METAIS PESADOS EM PERFIS DE SOLOS CONSTRUÍDOS EM ÁREA DE MINERAÇÃO DE CARVÃo
}

\author{
Dioni Glei Bonini Bitencourt ${ }^{(2)}$, Luiz Fernando Spinelli Pinto ${ }^{(2)}$, Eloy Antonio Pauletto ${ }^{(2)^{*}}$, \\ Mariana Tavares Silva ${ }^{(1)}$ e Gabriel Furtado Garcia $^{(3)}$
}

\footnotetext{
(1) Faculdade de Agronomia Eliseu Maciel, Departamento de Solos, Programa de Pós-Graduação em Agronomia, Capão do Leão, Rio Grande do Sul, Brasil.

(2) Faculdade de Agronomia Eliseu Maciel, Departamento de Solos, Capão do Leão, Rio Grande do Sul, Brasil.

(3) Faculdade de Agronomia Eliseu Maciel, Curso de Agronomia, Capão do Leão, Rio Grande do Sul, Brasil.

* Autor correspondente.

E-mail: pauletto_sul@yahoo.com.br
}

\section{RESUMO}

Os solos construídos após a extração de carvão a céu aberto são compostos do solo superficial e, ou, do estéril de mineração. As propriedades químicas desses solos diferem das propriedades dos solos naturais, principalmente em razão do processo de sulfurização. $O$ objetivo deste trabalho foi avaliar o potencial de acidificação da pirita e de contaminação com metais pesados ao longo de perfis de solos construídos após mineração de carvão, em áreas de diferentes idades, com e sem recuperação ambiental concomitante com a lavra. Foram selecionadas áreas mineradas denominadas de I e II, sem recuperação ambiental durante a lavra e compostas somente pelo estéril de mineração, representando as áreas mais antigas, e IV e VII, contendo topsoil e em alguns locais na camada de argila, constituindo as áreas mais jovens deste estudo. Foram coletadas amostras deformadas até $\mathbf{2} \mathbf{m}$ de profundidade. Analisaram-se granulometria, densidade de partículas, $\mathrm{pH}$ em água, $\mathrm{Ca}, \mathrm{Mg}, \mathrm{Al}, \mathrm{K}, \mathrm{Na}, \mathrm{P}, \mathrm{H}+\mathrm{Al}$, potencial de acidificação, potencial de neutralização, potencial líquido, teor de $\mathrm{C}$ orgânico e condutividade elétrica no extrato da pasta saturada. Também foram extraídos os metais potencialmente biodisponíveis pela metodologia USEPA $3050 \mathrm{~B}$, cujos resultados foram comparados com os valores orientadores de prevenção e investigação para solos. Na análise univariada, foi aplicada a estatística descritiva e o teste de aderência de Kolmogorov-Smirnov. O grau de dispersão de cada variável foi avaliado qualitativamente e classificado como: baixo, moderado ou alto. A análise multivariada de componentes principais foi realizada para os solos 
construídos das áreas I, II, IV e VII; posteriormente, foram construídos biplots dos primeiros componentes principais. Os solos construídos das áreas mais antigas evidenciaram menores pHs e significativo potencial de acidificação. As camadas superficiais de topsoil, dos solos das áreas IV e VII, apesar de proporcionar condições químicas favoráveis ao estabelecimento de culturas agrícolas, não evitaram a formação de drenagem ácida em profundidade. $O$ processo de sulfurização e sua relação com a liberação de metais foi melhor caracterizado pela análise de componentes principais realizada nas áreas IV e VII, em razão da correlação entre pH e saturação por bases nos estéreis só se expressar em saturações por bases acima de 40 \%, não observada nos materiais dos estéreis das áreas I e II.

Palavras-chave: áreas degradadas por mineração, pirita, contaminação por metais, análise de componentes principais.

\title{
ABSTRACT: PROCESS OF GENERATING ACID MINE DRAINAGE AND HEAVY METAL CONTAMINATION IN PROFILES OF REBUILT SOIL IN A COAL MINING AREA
}

\begin{abstract}
Soils rebuilt after coal strip mining is composed of topsoil and, or, overburden, and their chemical properties differ from those of natural soils mainly due to the sulfurization process. The objective of this study was to evaluate the potential for acidification from sulfides and heavy metal contamination across profiles of soils rebuilt after coal mining, in areas of different ages, with and without concomitant environmental reclamation during mine operations. Mining areas of different ages were selected: areas $I$ and II, without environmental reclamation during extraction and composed only from overburden, representing the oldest areas; and areas $I V$ and VII, containing topsoil and, in some profiles, a clay layer (B and BC horizons from the natural soil) between the topsoil and the overburden, constituting the younger rebuilt mine soils. Soil pits were opened and disturbed samples were collected up to a depth of $2 \mathrm{~m}$. Determinations were made of soil particle size, particle density, $\mathrm{pH}, \mathrm{Ca}, \mathrm{Mg}, \mathrm{Al}, \mathrm{K}, \mathrm{Na}, \mathrm{P}, \mathrm{H}+\mathrm{Al}$, acidity potential, neutralization potential, net potential, organic $C$ content, and electrical conductivity in saturated paste. In addition, potentially bioavailable metals were extracted by the USEPA $3050 B$ method (Fe, $\mathrm{Al}, \mathrm{Mn}, \mathrm{Ba}, \mathrm{Cu}, \mathrm{Zn}, \mathrm{C}, \mathrm{Cr}, \mathrm{Co}, \mathrm{Cd}, \mathrm{Pb}, \mathrm{Mo}, \mathrm{As}$, and $\mathrm{Se}$ ), and the results were compared to the guideline values of prevention and investigation for soils. In univariate analysis, descriptive statistics and the Kolmogorov-Smirnov test were applied. The degree of dispersion of each variable, expressed by the coefficient of variation, was qualitatively evaluated and classified as low, moderate, or high. Multivariate principal component analysis (PCA) was carried out for the constructed mine soils of areas I and II, and $I V$ and VII, and then biplots were applied to the first principal components. The rebuilt mine soils from the oldest areas (I and II) showed lower pH (<3.2) and higher acidification potential. The topsoil and clay layers in areas IV and VII, in spite of providing favorable chemical conditions for surface vegetation, did not prevent acid mine drainage from developing in the subsurface. The sulfurization process and its relationship to release of metals was best characterized by principal component analysis performed in soils from areas IV and VII because the correlation between $p H$ and base saturation in overburden layers is only expressed in base saturation above $40 \%$, which was not observed in rebuilt mine soils from areas I and II.
\end{abstract}

Keywords: degraded mining areas, pyrite, metal contamination, principal component analysis.

\section{INTRODUÇÃO}

A mineração é um dos setores básicos da economia nacional, contribuindo para o bem-estar e a melhoria da qualidade de vida da população, sendo fundamental para o progresso da sociedade, desde que seja operada com responsabilidade social, levando em conta os preceitos do desenvolvimento sustentável (Farias, 2002). O carvão mineral é a maior fonte de energia não renovável no Brasil e a sua exploração é de grande importância para a diversidade da matriz energética brasileira. No município de Candiota, RS, encontra-se a maior reserva carbonífera, possuindo aproximadamente
8 bilhões de toneladas de carvão, representando em torno de $37 \%$ do total das reservas do Estado e $33 \%$ das reservas do Brasil (DNPM, 2005). As camadas de carvão da jazida de Candiota fazem parte da formação Rio Bonito, sendo explorados dois bancos de carvão, separados por uma camada de argilito. O processo de extração de carvão em Candiota é realizado na forma de lavra a céu aberto em faixas, requerendo a retirada das camadas geológicas sobrejacentes ao carvão, que são misturadas durante a extração, denominadas de estéreis. Após a queima para a geração de energia na usina termoelétrica, as cinzas do carvão retornam à cava de mineração e sobre essas são 
depositados os estéreis da cava seguinte (Zanella, 1988), recompondo topograficamente a paisagem.

O processo de mineração e os equipamentos utilizados na reabilitação de áreas após a mineração de carvão influenciam as características dos solos construídos; por exemplo, a utilização de scrapers na mina Butiá-Leste, RS, criou solos construídos constituídos por uma sucessão irregular de camadas de estéreis com cores, espessuras e texturas variáveis, geralmente descontínuas e com transições abruptas (Kämpf et al., 1997), ao passo que a utilização de dragline, como em Candiota, RS, origina um solo construído constituído por uma mistura heterogênea de estéreis sobreposta por uma camada do solo superficial (topsoil). A recomposição topográfica e o espalhamento do topsoil com equipamentos pesados incorrem na perda de estrutura do solo, determinando, entre outras alterações, o aumento da densidade do solo ( $\mathrm{Ds}>1,6 \mathrm{Mg} \mathrm{m}^{-3}$ ) e as baixas taxas de infiltração de água no solo (Vib $<5 \mathrm{~cm} \mathrm{~h}^{-1}$ ) (Guebert e Gardner, 2001), que favorece o escoamento superficial e a erosão hídrica.

A pirita $\left(\mathrm{FeS}_{2}\right)$, encontrada no carvão, linhito e outras rochas sedimentares, quando exposta a um ambiente oxidante, dá início a um processo pedogenético denominado de sulfurização, onde os materiais contendo sulfetos são oxidados, formando ácido sulfúrico, gerando condições extremamente ácidas com $\mathrm{pH}<3$ (Pinto e Kämpf, 2002), intemperizando os minerais do solo, fazendo com que novas fases minerais sejam formadas pelos produtos dessa dissolução e elevando a concentração de metais como $\mathrm{Al}, \mathrm{Fe}, \mathrm{Mn}, \mathrm{Cu}, \mathrm{Ni}$ e Zn em níveis tóxicos (Barnhisel et al., 1982). A acidificação produzida acelera também as perdas de $\mathrm{Ca}$ e $\mathrm{Mg}$ por lixiviação na forma de sais de sulfato, além de provocar deficiência de $\mathrm{P}$, Mo e B. A contaminação do solo por metais pesados, além de prejudicar o desenvolvimento normal de muitas espécies de plantas e da microbiota do solo, contaminam os cursos de água naturais e o lençol freático (Kabata-Pendias, 2011). Essas reações químicas podem ocorrer tanto nos solos construídos como nas cavas abertas para extração e nas pilhas de rejeitos oriundas do processo de beneficiamento de carvão (Pinto e Kämpf, 2002), gerando a liberação de acidez para as águas de drenagem, processo esse conhecido como drenagem ácida da mina (DAM).

A legislação ambiental requer que as empresas mineradoras executem a reabilitação das áreas mineradas, de maneira que os solos construídos após a mineração proporcionem condições para o desenvolvimento vegetal (Pinto, 1997). Para o controle e a prevenção da acidificação, deve-se buscar a correção da acidez potencial do solo, mediante a aplicação de corretivos como o carbonato de cálcio, além de evitar a contaminação por pirita nas camadas mais superficiais dos solos construídos, confinando os materiais portadores desse mineral nas camadas mais profundas, dificultando assim o seu contato com água e oxigênio.

É fundamental o controle da erosão das áreas recuperadas, que deve ser realizado pelo manejo adequado, com práticas mecânicas e culturais que promovam o rápido estabelecimento da vegetação e manutenção da cobertura do solo ao longo do tempo. Caso contrário, a erosão poderá expor camadas subsuperficiais de estéril contaminadas com pirita, dando início à formação de sulcos com geração de drenagem ácida (Pinto e Kämpf, 2002).

Têm-se como hipóteses que a geração de drenagem ácida diminui tanto o potencial de neutralização como o de acidificação ao longo do tempo, e a diminuição do $\mathrm{pH}$ aumenta a liberação de metais.

O objetivo deste trabalho foi avaliar o potencial de acidificação da pirita e de contaminação com metais pesados ao longo de perfis de solos construídos após mineração de carvão em Candiota, RS, em áreas de diferentes idades, incluindo áreas antigas onde não foi realizada recuperação ambiental concomitante à lavra.

\section{MATERIAL E MÉTODOS}

O trabalho foi realizado na área de mineração de carvão da Companhia Rio-grandense de Mineração (CRM), no município de Candiota, RS, próximo à cidade de Bagé (Figura 1), distante $336 \mathrm{~km}$ de Porto Alegre, RS, e $150 \mathrm{~km}$ da cidade de Pelotas, RS. As camadas de carvão fazem parte da formação Rio Bonito (IBGE, 1986).

Foram selecionadas três áreas mineradas em diferentes épocas: área I, área II e áreas IV e VII (Figura 2). As áreas I e II foram locais minerados nas décadas de 1960 e 1970-1980, respectivamente, sem plano de recuperação ambiental durante a lavra, deixando somente as pilhas de estéreis, que foram posteriormente recompostas topograficamente e revegetadas com eucalipto. Nas áreas IV e VII, mineradas a partir da década de 1990 até o momento, com recuperação concomitante com a lavra, houve a colocação de topsoil. Em alguns locais, houve a adição de camada de argila (horizonte $\mathrm{B}$ e, ou, BC) entre os estéreis de mineração e a terra vegetal, e a revegetação foi realizada com gramíneas perenes, principalmente braquiárias (brizanta e humidícola) e pensacola; no inverno, com gramíneas anuais (aveia-preta).

Nas áreas I e II, foram escolhidos três perfis por área; e nas IV e VII, quatro perfis, sendo três na área IV e um na área VII (Figura 2). Nessas áreas, foram abertas trincheiras de $1,5 \times 1,5 \times 2,0 \mathrm{~m}$, com auxílio de retroescavadeira. 

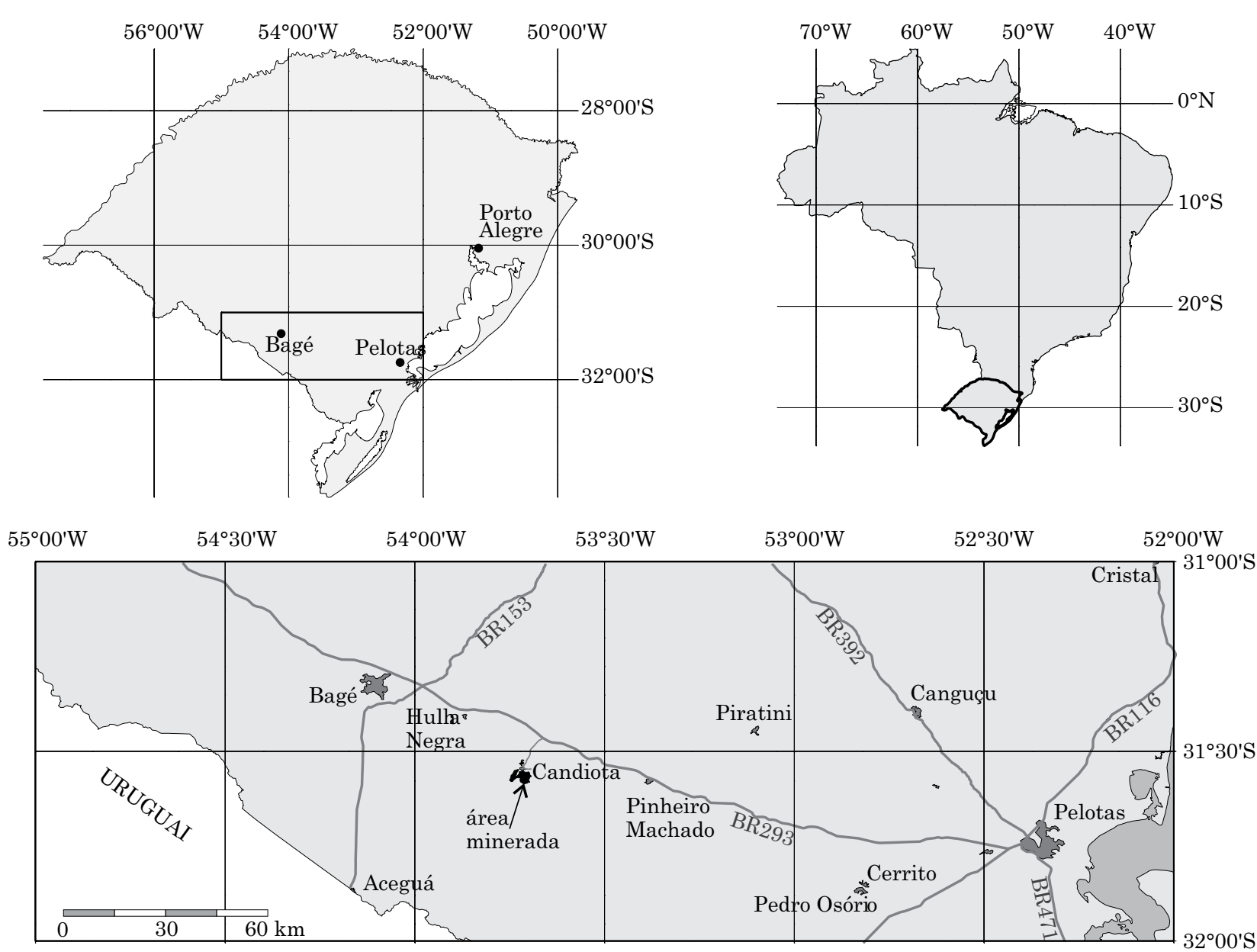

Figura 1. Localização da área de mineração de carvão situada no município de Candiota, no Estado do Rio Grande do Sul.

As amostras de solo foram coletadas em quatro profundidades ao longo da parede exposta da trincheira, a fim de obter-se uma amostra composta, englobando a variabilidade dos materiais existentes. Em razão da ausência da camada de topsoil, a coleta foi feita em quatro profundidades fixas nas trincheiras das áreas I e II: $0,00-0,10 ; 0,40-0,50 ; 1,00-1,10$; e $1,90-2,00 \mathrm{~m}$, ao passo que das IV e VII ocorreram variações por causa das espessuras das camadas de topsoil e, ou, de argila. A identificação, a composição e as idades dos perfis de solos construídos utilizados neste estudo constam no quadro 1.

As amostras de solo e de estéreis foram secas ao ar, homogeneizadas e posteriormente quarteadas para obter uma amostra de trabalho menor. Nas camadas de estéreis, foram separados os fragmentos grosseiros e consolidados (duros) de arenitos, siltitos e carvões, enquanto os fragmentos soltos e menos consolidados foram triturados e moídos de forma a passar numa peneira de malha de $2 \mathrm{~mm}$ para posterior análises de laboratório.
As análises físicas consistiram da determinação da granulometria pelo método da pipeta, com o uso de $\mathrm{NaOH} 1 \mathrm{~mol} \mathrm{~L}^{-1}$ como dispersante e agitação lenta por 16 h (Embrapa, 2011), e da densidade das partículas determinada pela relação massa/volume pelo método do picnômetro (Embrapa, 2011).

$\mathrm{Na}$ fração terra fina, foram analisados o $\mathrm{pH}$ em água, $\mathrm{Ca}^{2+}, \mathrm{Mg}^{2+}$ e $\mathrm{Al}^{3+}$ extraídos com $\mathrm{KCl} 1 \mathrm{~mol} \mathrm{~L}-1$; o K e Na trocáveis extraídos com solução Mehlich-1 $\left(\mathrm{HCl} 0,05 \mathrm{~mol} \mathrm{~L}^{-1}+\mathrm{H}_{2} \mathrm{SO}_{4} 0,0125 \mathrm{~mol} \mathrm{~L}^{-1}\right)$ e a acidez potencial com acetato de cálcio $0,5 \mathrm{~mol} \mathrm{~L}^{-1}$ a pH 7,0 (Embrapa, 2011). O teor de C orgânico do solo foi determinado pelo método de combustão de Walkley-Black (Tedesco et al., 1995). Ainda, na fração terra fina, foram extraídos os metais potencialmente biodisponíveis $\mathrm{Fe}, \mathrm{Al}, \mathrm{Mn}, \mathrm{Ba}, \mathrm{Cu}, \mathrm{Zn}, \mathrm{N}, \mathrm{Cr}, \mathrm{Co}, \mathrm{Pb}$, $\mathrm{Cd}, \mathrm{Mo}$, As e Se, conforme o método USEPA 3050B (Usepa, 1998), que utiliza $\mathrm{HNO}_{3} 1: 1$, determinados por ICP-OES. Os resultados foram comparados com os valores orientadores de prevenção e investigação (VP e VI) para solos (Conama, 2009). A condutividade elétrica (CE) foi medida no extrato da pasta saturada (Embrapa, 2011). 


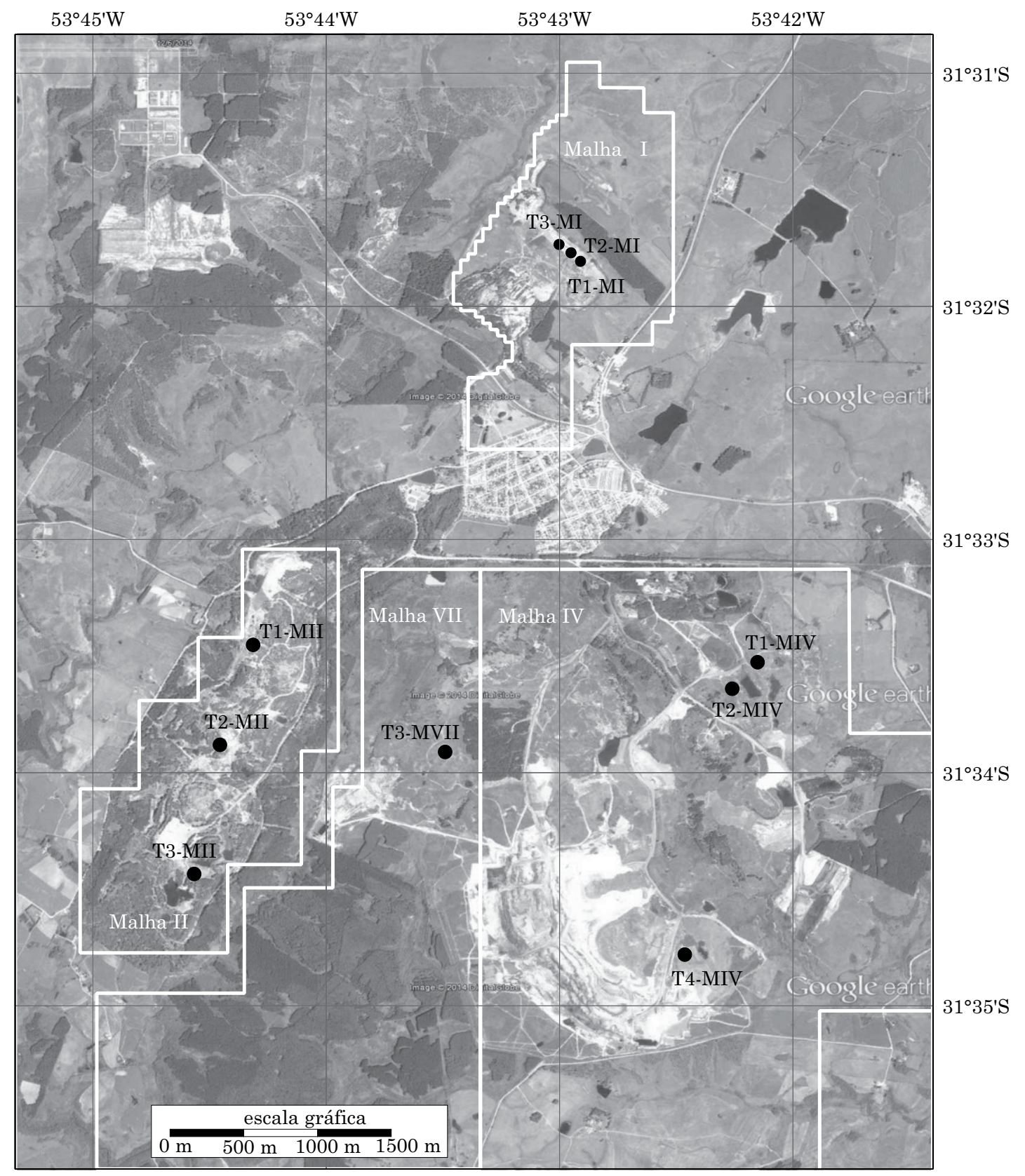

Figura 2. Área de mineração da Companhia Rio-grandense de Mineração em Candiota, RS, com as identificações das áreas (malhas) mineradas e das trincheiras.

Os potenciais de acidificação em razão da pirita (PA) e de neutralização por causa dos carbonatos $(\mathrm{PN})$ foram determinados pelo método de O'Shay et al. (1990), modificado por Pinto (1997), de forma a determinar o PN e o PA a partir da mesma amostra. Em todo conjunto de dados, foi aplicada a estatística descritiva (média, coeficiente de variação, valor máximo e mínimo), assim como o teste de aderência de KolmogorovSmirnov (Massey, 1951), a 5 \% de significância, para verificar a tendência de normalidade de cada distribuição de dados. O coeficiente de variação (CV) de cada conjunto de dados foi classificado segundo Wilding e Drees (1983): CV $\leq 15 \%$ - baixa dispersão dos dados; $15 \%<\mathrm{CV} \leq 35 \%$ - moderada dispersão; e CV $>35 \%$ - alta dispersão. Foi aplicada a análise de componentes principais (Jolliffe, 2002) para reduzir a dimensionalidade das variáveis para os solos construídos das áreas I e II e para os das IV e VII; após, foram construídos biplots dos componentes principais (Gabriel, 1971). 
Quadro 1. Identificação, composição e idade dos perfis de solos construídos utilizados neste estudo

\begin{tabular}{lcc}
\hline Identificação & Composição & Idade \\
\hline MI-T1 & Estéreis & 48 anos \\
MI-T2 & Estéreis & 48 anos \\
MI-T3 & Estéreis & 48 anos \\
MII-T1 & Estéreis & 32 anos \\
MII-T2 & Estéreis & 29 anos \\
MII-T3 & Estéreis & 23 anos \\
MIV-T1 & Topsoill estéreis & 22 anos \\
MIV-T2 & Topsoil/camada de argila/estéreis & 21 anos \\
MVII-T3 & Topsoil/estéreis & 14 anos \\
MIV-T4 & Topsoil/camada de argila/estéreis & 8 anos \\
\hline \multicolumn{3}{c}{}
\end{tabular}

\section{RESULTADOS E DISCUSSÃO}

\section{Caracterização das propriedades físicas e químicas dos solos construídos}

Os materiais das camadas de estéril de mineração dos perfis de todas as áreas apresentaram quantidades elevadas de silte e argila (Quadro 2), concordando com a composição da coluna geológica local, constituída por siltitos, argilitos e folhelhos carbonosos e por menores quantidades de arenitos, com os dados apresentando distribuição normal e dispersão de valores classificada como moderada e alta (Quadro 4), conforme Wilding e Drees (1983). As camadas de topsoil, à exceção do perfil MVII-T3, exibiram maiores valores de areia, em consonância com a origem do solo natural (Argissolo desenvolvido de arenito). No caso do perfil MVII-T3, que indicou menores valores de areia e maiores de argila (Quadro 2), esse evidenciou ser composto predominantemente pelo horizonte B do Argissolo.

A soma de bases (SB) das camadas de estéril dos perfis das áreas IV e VII apresentou valores mais elevados em relação à área II e essa superior à da I, sendo o mesmo comportamento observado para os valores de saturação por bases (V) e situação inversa em relação aos teores de $\mathrm{Al}$ (Quadro 2). O observado indica que os solos das áreas I e II, mais antigos e sem camadas de topsoil e argila, sofreram maior lixiviação ao longo do seu perfil, o que levou à perda dos cátions básicos e acúmulo de cátions ácidos $(\mathrm{Al}$ e $\mathrm{H})$, deslocando assim o equilíbrio ácido-base para a faixa mais ácida, o que é confirmado pelo aumento da $\mathrm{V} \mathrm{e}$ pela diminuição do $\mathrm{Al}$ em profundidade nos estéreis dessas áreas (Quadro 2), resultado semelhante encontrado por Campos et al. (2003). Essas variáveis apresentaram distribuição normal de acordo com o teste $\mathrm{KS}$ e $\mathrm{CV}>35 \%$, indicando alta dispersão (Quadro 3). Em razão das bases, o pH das áreas IV e VII apresentou valores superiores em relação às áreas I e II, com os menores valores de $\mathrm{pH}$ sendo encontrados nas camadas mais superficiais das áreas I e II (Quadro 2), o que pode explicar a distribuição não normal para essa variável independentemente da sua mensuração em escala logarítmica; além disso, o pH exibiu moderada dispersão (Quadro 3).

A relação entre o $\mathrm{pH}$ e a saturação por bases dos perfis de solos construídos das áreas I, II, IV e VII é apresentada na figura 3. Foi obtida uma faixa ampla de variação da saturação por bases, tanto para os materiais das camadas de estéril como para topsoil e argila, desde menos de 20 até aproximadamente $80 \%$. Porém, há um padrão diferente nos valores de pH entre os materiais do estéril e da topsoil e argila. Para as camadas superficiais de topsoil e argila das áreas IV e VII, esse variou de 4,0 a 7,0, exibindo um coeficiente de correlação com a saturação por bases de 0,94 . Nos estéreis de mineração, a variação foi de 2,0 a 4,0, com $r=0,11$ e 0,89 , para os estéreis das áreas I e II e das IV e VII, respectivamente (Figura 3). A baixa correlação dos estéreis das áreas I e II em contraste com a das áreas IV e VII indica que as bases nesse sistema atuam de forma mais significativa sobre o $\mathrm{pH}$, a partir de valores de $\mathrm{V}$ acima de $40 \%$. Dessa forma, fica denotado um sistema de equilíbrio ácido-base distinto entre as camadas de estéril e de topsoil e argila, onde os valores de V estão sob efeito do processo de sulfurização, como evidenciado pelos baixos pHs e pelas altas condutividades elétricas (Quadro 2); altas saturações por bases são necessárias para manter $\mathrm{pHs}$ relativamente baixos, em torno de 4,0 a 4,5 com V de $80 \%$.

Os valores mais elevados de $\mathrm{Al}$ nas áreas I e II devem-se ao ambiente mais extremo de acidificação (pH entre 2,23 e 3,19), onde se desenvolve a fase catalítica de oxidação da pirita, com a oxidação realizada pelo $\mathrm{Fe}$ férrico, produzindo 16 moles de $\mathrm{H}^{+}$ para cada mol de pirita (Singer e Stumm, 1970). Nesse sistema, os aluminos silicatos se desestabilizam, liberando o $\mathrm{Al}$ de sua estrutura, que desloca os cátions básicos dos sítios de troca, lixiviando-os.

Os teores de $\mathrm{C}$ no topsoil dos perfis das áreas IV e VII variaram de 8 a $22 \mathrm{~g} \mathrm{~kg}^{-1}$ de solo (Quadro 2), com valores inferiores relacionados à presença do horizonte B no perfil MVII-T3. Entretanto, os estéreis de mineração de todas as áreas apresentaram teores mais elevados de $\mathrm{C}$, entre 20 e $59 \mathrm{~g} \mathrm{~kg}^{-1}$, o que pode ser explicado pela presença de fragmentos de carvão e de rochas carbonosas, que estão disseminados em toda a massa de estéril, cujo $\mathrm{C}$ pode ter sido parcialmente oxidado pelo método Walkley-Black. O C apresentou distribuição normal e alta dispersão (Quadro 3).

Os solos construídos da área II apresentaram maiores valores do potencial de acidificação (PA) em relação aos da I; e o potencial de neutralização (PN) é praticamente nulo para esses solos (Quadro 4). Admitindo a homogeneidade do material geológico em relação à pirita nesses solos, a diferença entre esses potenciais de acidificação pode ser atribuída às idades de mineração dessas áreas. As reações de oxidação 
Quadro 2. Propriedades físicas e químicas dos perfis de solos construídos com diferentes idades

\begin{tabular}{|c|c|c|c|c|c|c|c|c|c|c|c|c|c|c|c|c|c|}
\hline $\begin{array}{l}\text { Perfil } \\
\text { (Idade) }\end{array}$ & $\mathbf{N}^{\circ}$ & Prof. $^{(1)}$ & Areia & Silte & Argila & CE & $\mathrm{pH}\left(\mathrm{H}_{2} \mathrm{O}\right)$ & $\mathrm{Ca}^{2+}$ & $\mathrm{Mg}^{2+}$ & $\mathbf{K}^{+}$ & $\mathrm{Na}^{+}$ & SB & $\mathrm{Al}^{3+}$ & $\mathbf{H}^{+}$ & $\mathrm{CTC}^{(2)}$ & $V^{(3)}$ & $\mathrm{CO}^{(4)}$ \\
\hline & & $\mathrm{m}$ & & $\mathrm{g} \mathrm{kg}^{-1}$ & & $\mathrm{dS} / \mathrm{m}$ & & & & & $\mathrm{cmo}$ & $\mathrm{l}_{\mathrm{c}} \mathrm{kg}^{-1}$ & & & & $\%$ & $\mathrm{~g} \mathrm{~kg}^{-1}$ \\
\hline \multirow{4}{*}{$\begin{array}{l}\text { MI-T1 } \\
\text { (44 anos) }\end{array}$} & 1 & $0,00-0,10$ & 87 & 405 & 508 & 11,44 & 2,36 & 1,27 & 0,90 & 0,02 & 0,03 & 2,22 & 25,90 & 9,33 & 37,45 & 5,94 & 41 \\
\hline & 2 & $0,40-0,50$ & 187 & 358 & 455 & 11,58 & 2,41 & 1,43 & 0,67 & 0,01 & 0,12 & 2,24 & 21,33 & 7,92 & 31,49 & 7,11 & 41 \\
\hline & 3 & $1,00-1,10$ & 151 & 363 & 487 & 7,42 & 2,63 & 1,99 & 0,64 & 0,04 & 0,17 & 2,84 & 13,44 & 6,85 & 23,13 & 12,30 & 38 \\
\hline & 4 & $1,90-2,00$ & 233 & 307 & 460 & 7,55 & 2,59 & 1,86 & 0,73 & *0,002 & 0,08 & 2,68 & 16,54 & 6,48 & 25,70 & 10,41 & 31 \\
\hline \multirow{4}{*}{$\begin{array}{l}\text { MI-T2 } \\
\text { (44 anos) }\end{array}$} & 5 & $0,00-0,10$ & 246 & 291 & 464 & 10,05 & 2,51 & 1,56 & 2,53 & 0,03 & 0,02 & 4,15 & 19,39 & 5,65 & 29,19 & 14,22 & 20 \\
\hline & 6 & $0,40-0,50$ & 193 & 326 & 481 & 11,40 & 2,48 & 4,19 & 4,31 & 0,03 & 0,07 & 8,59 & 18,44 & 4,27 & 31,31 & 27,44 & 27 \\
\hline & 7 & $1,00-1,10$ & 234 & 343 & 423 & 10,23 & 2,75 & 3,53 & 4,20 & 0,06 & 0,20 & 7,97 & 12,53 & 3,09 & 23,60 & 33,80 & 28 \\
\hline & 8 & $1,90-2,00$ & 223 & 347 & 430 & 6,92 & 2,94 & 4,19 & 2,63 & 0,35 & 0,30 & 7,47 & 8,76 & 2,95 & 19,18 & 38,95 & 24 \\
\hline \multirow{4}{*}{$\begin{array}{l}\text { MI-T3 } \\
\text { (44 anos) }\end{array}$} & 9 & $0,00-0,10$ & 261 & 308 & 432 & 2,88 & 2,86 & 0,52 & 0,19 & 0,34 & 0,03 & 1,07 & 11,16 & 5,68 & 17,92 & 5,99 & 26 \\
\hline & 10 & $0,40-0,50$ & 218 & 308 & 474 & 1,75 & 2,98 & 1,12 & 0,17 & 0,16 & 0,02 & 1,47 & 10,00 & 9,09 & 20,56 & 7,13 & 33 \\
\hline & 11 & $1,00-1,10$ & 306 & 277 & 418 & 1,23 & 3,14 & 0,28 & 0,11 & 0,30 & 0,02 & 0,71 & 9,21 & 7,64 & 17,56 & 4,07 & 31 \\
\hline & 12 & $1,90-2,00$ & 244 & 374 & 383 & 1,14 & 3,18 & 0,26 & 0,11 & 0,31 & 0,02 & 0,70 & 9,86 & 7,50 & 18,05 & 3,89 & 32 \\
\hline \multirow{4}{*}{$\begin{array}{l}\text { MII-T1 } \\
\text { (28 anos) }\end{array}$} & 13 & $0,00-0,10$ & 326 & 311 & 363 & 9,41 & 2,28 & 3,90 & 0,50 & ${ }^{*} 0,002$ & 0,01 & 4,41 & 17,28 & 8,20 & 29,90 & 14,75 & 51 \\
\hline & 14 & $0,40-0,50$ & 318 & 261 & 422 & 13,45 & 2,23 & 6,39 & 0,72 & $*^{*} 0,002$ & 0,02 & 7,13 & 24,38 & 6,01 & 37,52 & 19,01 & 34 \\
\hline & 15 & $1,00-1,10$ & 264 & 315 & 422 & 4,15 & 2,53 & 7,02 & 1,00 & 0,04 & 0,02 & 8,08 & 20,70 & 2,40 & 31,18 & 25,91 & 33 \\
\hline & 16 & $1,90-2,00$ & 289 & 258 & 453 & 10,75 & 2,42 & 1,56 & 1,37 & 0,13 & 0,04 & 3,09 & 19,60 & 2,21 & 24,90 & 12,42 & 38 \\
\hline \multirow{4}{*}{$\begin{array}{l}\text { MII-T2 } \\
\text { (25 anos) }\end{array}$} & 17 & $0,00-0,10$ & 234 & 309 & 457 & 1,74 & 3,00 & 1,56 & 0,31 & 0,29 & 0,03 & 2,19 & 11,03 & 6,33 & 19,55 & 11,20 & 41 \\
\hline & 18 & $0,40-0,50$ & 324 & 233 & 443 & 4,08 & 2,66 & 5,78 & 0,47 & 0,18 & 0,05 & 6,48 & 10,96 & 5,66 & 23,11 & 28,06 & 34 \\
\hline & 19 & $1,00-1,10$ & 307 & 321 & 373 & 4,27 & 2,88 & 7,77 & 1,12 & 0,33 & 0,06 & 9,27 & 9,95 & 4,65 & 23,86 & 38,85 & 34 \\
\hline & 20 & $1,90-2,00$ & 149 & 405 & 446 & 8,40 & 2,67 & 9,73 & 3,87 & 0,32 & 0,14 & 14,07 & 12,11 & 5,47 & 31,64 & 44,46 & 49 \\
\hline \multirow{4}{*}{$\begin{array}{l}\text { MII-T3 } \\
\text { (19 anos) }\end{array}$} & 21 & $0,00-0,10$ & 193 & 411 & 396 & 1,64 & 3,11 & 2,34 & 0,29 & 0,32 & 0,03 & 2,99 & 10,39 & 8,82 & 22,20 & 13,45 & 45 \\
\hline & 22 & $0,40-0,50$ & 190 & 402 & 408 & 3,52 & 2,68 & 4,88 & 0,43 & 0,23 & 0,03 & 5,58 & 11,92 & 12,50 & 30,00 & 18,59 & 59 \\
\hline & 23 & $1,00-1,10$ & 306 & 261 & 434 & 4,45 & 2,82 & 6,76 & 0,53 & 0,24 & 0,10 & 7,64 & 9,88 & 9,64 & 27,17 & 28,12 & 45 \\
\hline & 24 & $1,90-2,00$ & 374 & 234 & 392 & 3,70 & 3,19 & 7,56 & 0,84 & 0,42 & 0,15 & 8,96 & 9,05 & 3,33 & 21,35 & 41,99 & 29 \\
\hline \multirow{4}{*}{$\begin{array}{l}\text { MIV-T1 } \\
\text { (18 anos) }\end{array}$} & 1 & $0,00-0,10$ & 411 & 229 & 360 & 0,19 & 4,72 & 2,39 & 1,05 & 0,32 & 0,01 & 3,77 & 3,78 & 4,77 & 12,32 & 30,61 & 22 \\
\hline & 2 & $0,60-0,70$ & 140 & 409 & 451 & 4,16 & 2,88 & 4,74 & 1,78 & 0,29 & 0,02 & 6,84 & 10,78 & 5,18 & 22,80 & 29,99 & 24 \\
\hline & 3 & $1,00-1,10$ & 168 & 396 & 436 & 4,71 & 3,18 & 8,92 & 4,38 & 0,50 & 0,08 & 13,88 & 6,98 & 3,73 & 24,59 & 56,45 & 29 \\
\hline & 4 & $1,90-2,00$ & 144 & 483 & 372 & 4,72 & 4,12 & 12,37 & 5,93 & 0,71 & 0,19 & 19,20 & 2,91 & 2,22 & 24,33 & 78,91 & 29 \\
\hline \multirow{4}{*}{$\begin{array}{l}\text { MIV-T2 } \\
\text { (17 anos) }\end{array}$} & 5 & $0,00-0,10$ & 466 & 205 & 330 & 0,23 & 5,07 & 2,43 & 1,30 & 0,65 & 0,02 & 4,40 & 1,66 & 5,02 & 11,09 & 39,72 & 17 \\
\hline & 6 & $0,60-0,70$ & 443 & 172 & 385 & 0,60 & 3,75 & 0,85 & 0,52 & 0,12 & 0,01 & 1,50 & 6,29 & 4,68 & 12,47 & 12,01 & 11 \\
\hline & 7 & $1,00-1,10$ & 233 & 330 & 438 & 5,80 & 2,78 & 5,25 & 2,02 & 0,24 & 0,11 & 7,61 & 10,11 & 11,76 & 29,48 & 25,83 & 40 \\
\hline & 8 & $1,90-2,00$ & 247 & 352 & 401 & 5,48 & 3,15 & 7,39 & 3,52 & 0,39 & 0,30 & 11,60 & 5,35 & 7,55 & 24,50 & 47,35 & 43 \\
\hline \multirow{4}{*}{$\begin{array}{l}\text { MVII-T3 } \\
\text { (10 anos) }\end{array}$} & 9 & $0,00-0,10$ & 325 & 227 & 448 & 0,23 & 7,09 & 6,02 & 3,68 & 0,41 & 0,01 & 10,12 & 0,14 & 2,28 & 12,55 & 80,70 & 8 \\
\hline & 10 & $0,60-0,70$ & 258 & 334 & 408 & 3,66 & 3,40 & 6,56 & 3,82 & 0,33 & 0,10 & 10,80 & 4,39 & 7,70 & 22,88 & 47,18 & 34 \\
\hline & 11 & $1,00-1,10$ & 189 & 403 & 408 & 4,71 & 4,02 & 9,43 & 6,45 & 0,46 & 0,19 & 16,53 & 2,19 & 5,70 & 24,41 & 67,71 & 37 \\
\hline & 12 & $1,90-2,00$ & 190 & 426 & 384 & 5,21 & 3,88 & 8,53 & 5,99 & 0,44 & 0,20 & 15,16 & 2,21 & 5,48 & 22,86 & 66,33 & 37 \\
\hline \multirow{4}{*}{$\begin{array}{l}\text { MIV-T4 } \\
\text { (4 anos) }\end{array}$} & 13 & $0,00-0,10$ & 422 & 274 & 304 & 0,30 & 5,12 & 3,50 & 1,85 & 0,19 & 0,04 & 5,58 & 0,31 & 4,28 & 10,18 & 54,83 & 8 \\
\hline & 14 & $0,60-0,70$ & 362 & 406 & 232 & 0,07 & 5,45 & 4,99 & 3,15 & 0,11 & 0,14 & 8,39 & 1,30 & 2,20 & 11,89 & 70,56 & 1 \\
\hline & 15 & $1,00-1,10$ & 104 & 456 & 440 & 9,76 & 2,37 & 11,45 & 5,55 & 0,15 & 0,28 & 17,44 & 18,43 & 7,77 & 43,63 & 39,97 & 45 \\
\hline & 16 & $1,90-2,00$ & 127 & 609 & 264 & 5,52 & 4,48 & 14,40 & 11,91 & 0,52 & 1,15 & 27,98 & 1,64 & 5,68 & 35,30 & 79,27 & 24 \\
\hline
\end{tabular}

(1) Prof.: profundidade da camada de solo; (2) Capacidade de troca de cátions a pH 7,0; (3) V: saturação por bases; (4) CO: carbono orgânico. Sombreado cinza identifica as camadas onde houve a colocação de terra vegetal; e cinza-escuro, as camadas de argila. * Valor referente ao limite de detecção do equipamento utilizado para leitura da amostra. 
Quadro 3. Estatística descritiva e teste de Kolmogorov-Smirnov (KS) para os atributos físicos, químicos e metais pesados dos perfis de solos construídos

\begin{tabular}{|c|c|c|c|c|c|c|c|c|c|c|c|c|}
\hline \multirow{2}{*}{ Atributo } & \multicolumn{2}{|c|}{ Média } & \multicolumn{2}{|c|}{$\mathbf{C V}^{(1)}$} & \multicolumn{2}{|c|}{ Mínimo } & \multicolumn{2}{|c|}{ Máximo } & \multicolumn{2}{|c|}{$\mathrm{D}^{(2)}$} & \multicolumn{2}{|c|}{$\mathbf{p}$} \\
\hline & I e II & IV e VII & I e II & IV e VII & I e II & IV e VII & I e II & IV e VII & I e II & IV e VII & I e II & IV e VII \\
\hline & & & \multicolumn{2}{|c|}{$\%$} & & & & & & & & \\
\hline Areia $\left(\mathrm{g} \mathrm{kg}^{-1}\right)$ & 244 & 264 & 27,7 & 46,7 & 87 & 104 & 374 & 466 & 0,11 & 0,16 & 0,90 & 0,72 \\
\hline Silte $\left(\mathrm{g} \mathrm{kg}^{-1}\right)$ & 322 & 357 & 16,6 & 32,5 & 233 & 172 & 411 & 609 & 0,10 & 0,13 & 0,96 & 0,91 \\
\hline Argila $\left(\mathrm{g} \mathrm{kg}^{-1}\right)$ & 434 & 379 & 8,5 & 17,5 & 363 & 232 & 508 & 451 & 0,08 & 0,16 & 1,00 & 0,77 \\
\hline $\left.\mathrm{CE}(\mathrm{dS} \mathrm{m})^{-1}\right)^{(3)}$ & 6,38 & 3,46 & 61,7 & 82,8 & 1,14 & 0,07 & 13,45 & 9,76 & 0,19 & 0,22 & 0,32 & 0,39 \\
\hline $\mathrm{pH}\left(\mathrm{H}_{2} \mathrm{O}\right)$ & 2,72 & 4,09 & 10,7 & 29,5 & 2,23 & 2,37 & 3,19 & 7,09 & 0,10 & 0,12 & 0,96 & 0,97 \\
\hline $\mathrm{Ca}^{2+}\left(\mathrm{cmol}_{\mathrm{c}} \mathrm{kg}^{-1}\right)$ & 3,64 & 6,83 & 75,7 & 56,2 & 0,26 & 0,85 & 9,73 & 14,40 & 0,18 & 0,10 & 0,35 & 0,99 \\
\hline $\mathrm{Mg}^{2+}\left(\mathrm{cmol}_{\mathrm{c}} \mathrm{kg}^{-1}\right)$ & 1,19 & 3,93 & 109,3 & 72,4 & 0,11 & 0,52 & 4,31 & 11,91 & 0,27 & 0,14 & 0,05 & 0,87 \\
\hline $\mathrm{K}^{+}\left(\mathrm{cmol}_{\mathrm{c}} \mathrm{kg}^{-1}\right)$ & 0,17 & 0,36 & 82,8 & 49,4 & 0,00 & 0,11 & 0,42 & 0,71 & 0,20 & 0,08 & 0,25 & 1,00 \\
\hline $\mathrm{Na}^{+}\left(\mathrm{cmol}_{\mathrm{c}} \mathrm{kg}^{-1}\right)$ & 0,07 & 0,18 & 99,5 & 155,2 & 0,01 & 0,01 & 0,30 & 1,15 & 0,22 & 0,28 & 0,15 & 0,13 \\
\hline $\mathrm{SB}\left(\mathrm{cmol}_{\mathrm{c}} \mathrm{kg}^{-1}\right)^{(4)}$ & 5,08 & 11,30 & 67,9 & 60,6 & 0,70 & 1,50 & 14,07 & 27,98 & 0,18 & 0,11 & 0,40 & 0,98 \\
\hline $\mathrm{Al}^{3+}\left(\mathrm{cmol}_{\mathrm{c}} \mathrm{kg}^{-1}\right)$ & 14,33 & 4,90 & 36,6 & 98,4 & 8,76 & 0,14 & 25,90 & 18,43 & 0,22 & 0,17 & 0,18 & 0,70 \\
\hline $\mathrm{H}^{+}\left(\mathrm{cmol}_{\mathrm{c}} \mathrm{kg}^{-1}\right)$ & 6,32 & 5,38 & 40,9 & 45,9 & 2,21 & 2,20 & 12,50 & 11,76 & 0,08 & 0,20 & 0,99 & 0,50 \\
\hline CTC $\left(\mathrm{cmol}_{\mathrm{c}} \mathrm{kg}^{-1}\right)^{(5)}$ & 25,73 & 21,58 & 23,0 & 44,1 & 17,56 & 10,18 & 37,52 & 43,63 & 0,12 & 0,20 & 0,81 & 0,46 \\
\hline $\mathrm{V}(\%)^{(6)}$ & 19,50 & 51,71 & 66,2 & 40,8 & 3,89 & 12,01 & 44,46 & 80,70 & 0,19 & 0,13 & 0,34 & 0,91 \\
\hline $\mathrm{CO}\left(\mathrm{g} \mathrm{kg}^{-1}\right)^{(7)}$ & 36 & 26 & 25,7 & 53,0 & 20 & 1 & 59 & 45 & 0,16 & 0,12 & 0,52 & 0,96 \\
\hline $\mathrm{PN}\left(\mathrm{kg} \mathrm{Mg}^{-1} \mathrm{CaCO}_{3}\right)^{(8)}$ & $<0,01$ & 3,17 & 0,0 & 90,8 & $<0,01$ & $<0,01$ & $<0,01$ & 7,77 & 1,00 & 0,21 & $<2,2 \mathrm{E}-16$ & 0,45 \\
\hline $\mathrm{PA}\left(\mathrm{kg} \mathrm{CaCO}_{3} \mathrm{Mg}^{-1}\right)^{(9)}$ & 12,9 & 4,8 & 56,6 & 75,9 & 5,38 & 0,31 & 32,5 & 10,4 & 0,28 & 0,23 & 0,04 & 0,31 \\
\hline $\mathrm{PL}\left(\mathrm{kg} \mathrm{CaCO}_{3} \mathrm{Mg}^{-1}\right)^{(10)}$ & $-12,9$ & $-1,6$ & 56,6 & $-316,0$ & $-32,48$ & $-9,32$ & $-5,4$ & 7,2 & 0,28 & 0,10 & 0,04 & 1,00 \\
\hline $\mathrm{Ba}\left(\mathrm{mg} \mathrm{kg}^{-1}\right)$ & 74 & 63 & 53,7 & 26,2 & 45 & 34 & 237 & 90 & 0,26 & 0,12 & 0,07 & 0,96 \\
\hline $\operatorname{Mn}\left(\mathrm{mg} \mathrm{kg}^{-1}\right)$ & 18 & 117 & 92,0 & 64,0 & 8 & 38 & 90 & 266 & 0,31 & 0,22 & 0,02 & 0,39 \\
\hline $\mathrm{Fe}\left(\mathrm{mg} \mathrm{kg}^{-1}\right)$ & 9.089 & 11.726 & 33,9 & 43,3 & 4.705 & 5.951 & 16.355 & 22.372 & 0,16 & 0,29 & 0,54 & 0,11 \\
\hline $\mathrm{Cu}\left(\mathrm{mg} \mathrm{kg}^{-1}\right)$ & 15 & 19 & 62,3 & 33,4 & 8 & 13 & 55 & 39 & 0,22 & 0,33 & 0,15 & 0,05 \\
\hline $\mathrm{Zn}\left(\mathrm{mg} \mathrm{kg}^{-1}\right)$ & 24 & 41 & 56,1 & 115,2 & 9 & 13 & 63 & 213 & 0,18 & 0,37 & 0,35 & 0,02 \\
\hline $\mathrm{Ni}\left(\mathrm{mg} \mathrm{kg}^{-1}\right)$ & 9 & 11 & 47,3 & 59,8 & 3 & 3 & 16 & 22 & 0,11 & 0,23 & 0,88 & 0,31 \\
\hline $\mathrm{Cr}\left(\mathrm{mg} \mathrm{kg}^{-1}\right)$ & 9 & 13 & 29,2 & 73,3 & 6 & 5 & 18 & 40 & 0,22 & 0,22 & 0,18 & 0,37 \\
\hline $\mathrm{Co}\left(\mathrm{mg} \mathrm{kg}^{-1}\right)$ & 8 & 8 & 43,2 & 39,8 & 2 & 3 & 14 & 12 & 0,15 & 0,14 & 0,61 & 0,88 \\
\hline $\mathrm{Pb}\left(\mathrm{mg} \mathrm{kg}^{-1}\right)$ & 20 & 20 & 17,3 & 12,8 & 13 & 16 & 26 & 24 & 0,18 & 0,21 & 0,37 & 0,40 \\
\hline $\mathrm{Cd}\left(\mathrm{mg} \mathrm{kg}^{-1}\right)$ & 0,1 & 0,1 & 0,0 & 0,0 & 0,1 & 0,1 & 0,1 & 0,1 & 1,00 & 1,00 & $<2,2 \mathrm{E}-16$ & $<2,2 \mathrm{E}-16$ \\
\hline Mo $\left(\mathrm{mg} \mathrm{kg}^{-1}\right)$ & 4,55 & 1,27 & 140,7 & 65,2 & 0,10 & 0,10 & 33,00 & 3,00 & 0,39 & 0,25 & $9,0 \mathrm{E}-04$ & 0,22 \\
\hline As $\left(\mathrm{mg} \mathrm{kg}^{-1}\right)$ & 8,44 & 10,39 & 79,6 & 95,7 & 0,15 & 0,15 & 22,00 & 30,00 & 0,15 & 0,17 & 0,57 & 0,68 \\
\hline $\mathrm{Se}\left(\mathrm{mg} \mathrm{kg}^{-1}\right)$ & 9 & 1 & 72,0 & 0,0 & 1 & 1 & 22,0 & 1,0 & 0,16 & 1,00 & 0,51 & $<2,2 \mathrm{E}-16$ \\
\hline
\end{tabular}

(1) CV: coeficiente de variação; ${ }^{(2)} \mathrm{D}$ : valor da estatística de Kolmogorov-Smirnov; ${ }^{(3)} \mathrm{CE}$ : condutividade elétrica; ${ }^{(4)}$ SB: soma de bases; ${ }^{(5)}$ CTC: capacidade de troca de cátions a pH 7,0; ${ }^{(6)} \mathrm{V}$ : saturação por bases; ${ }^{(7)} \mathrm{CO}$ : carbono orgânico; ${ }^{\left({ }^{8}\right)} \mathrm{PN}$ : potencial de neutralização;

(9) PA: potencial de acidificação; ${ }^{(10)}$ PL: potencial líquido de acidificação.

da pirita teriam se iniciado há mais tempo na área I (44 anos em média), o que influenciaria seu atual PA. Entretanto, o estéril das áreas IV e VII, mais jovens, exibe PAs inferiores comparativamente aos estéreis das I e II (Quadro 4), o que pode indicar uma diferença na composição das camadas geológicas, onde essas seriam portadoras de menores quantidade de sulfetos. A presença do PN nos estéreis das áreas IV e VII, que diminuiu o potencial líquido de acidificação (PL), pode ser uma indicação nesse sentido; no entanto, como esse sempre foi negativo a tendência continua a de acidificar o meio (Quadro 4). Dos potenciais avaliados, apenas o de neutralização não apresentou distribuição normal (Quadro 3), pois houve valores considerados nulos nas áreas I e II, contrastando com valores significativos nas áreas que foram recuperadas com colocação de topsoil e argila (Quadro 4). Essas propriedades químicas exibiram os maiores CVs e possuíam alta dispersão (CV > 35 \%). 


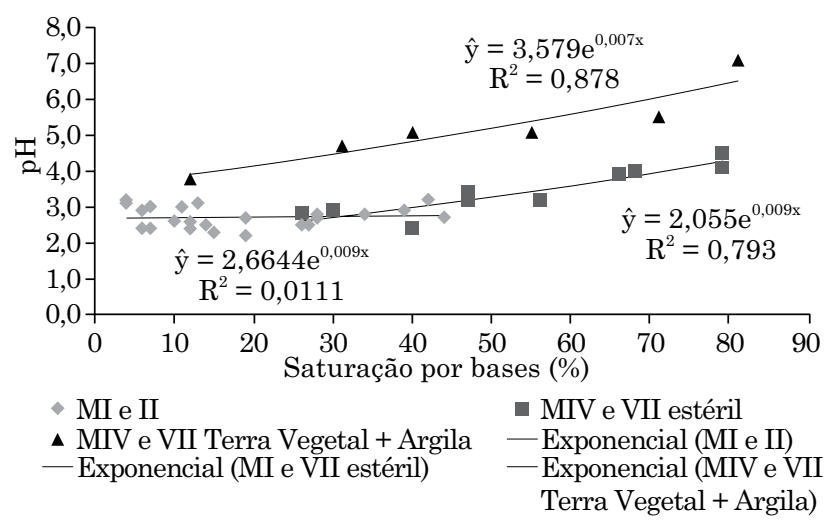

Figura 3. Relação entre pH e saturação por bases das áreas I, II, IV e VII. Áreas I e II: locais minerados nas décadas de 1960 e 1970-1980, respectivamente, sem plano de recuperação ambiental durante a lavra, deixando somente as pilhas de estéreis, que foram posteriormente recompostas topograficamente e revegetadas com eucalipto. Áreas IV e VII: mineradas a partir da década de 1990 até o momento, com recuperação concomitante com a lavra, houve a colocação de topsoil; em alguns locais, houve a adição de camada de argila (horizonte $B$ e, ou, BC) entre os estéreis de mineração e a terra vegetal, e a revegetação foi realizada com gramíneas perenes, principalmente braquiárias (brizanta e humidícola) e pensacola; no inverno, com gramíneas anuais (aveia-preta).

$\mathrm{O} \mathrm{Fe}$ e os metais $\mathrm{Mn}, \mathrm{Cu}, \mathrm{Zn}, \mathrm{Cr}, \mathrm{Cd}, \mathrm{Mo}$ e Se não apresentaram distribuição normal, exibindo CV entre 0 e 160,7 \% (Quadro 3) e alta dispersão, com exceção do Cd que apresentou CV nulo, porque as concentrações desse elemento sempre estiveram abaixo do limite de detecção do equipamento (Quadro 4).

Altos valores de Fe tanto nas amostras de solo dos estéreis quanto da topsoil foram detectados (Quadro 4). Isso indica que o método USEPA 3050B extraiu tanto o Fe proveniente da pirita, nos estéreis, como dos óxidos de Fe no topsoil e nas camadas de argila. As concentrações de todos os metais pesados analisados estão abaixo do limite de investigação para áreas agrícolas, de acordo com Resolução Conama $n^{\circ}$ 420/2009 (Quadro 4), indicando que os materiais geológicos do estéril não possuem teores naturais elevados de metais pesados. Porém, ocorreram valores superiores ao limite de prevenção (VP) para As (VP >15 mg kg-1) em seis perfis (MI-T2, MI-T3, MII-T1, MII-T2, MIV-T2 e MVII-T3); para Se (VP $>5 \mathrm{mg} \mathrm{kg}^{-1}$ ) em cinco perfis (MI-T1, MI-T2, MI-T3, MII-T1 e MII-T2); Mo (VP >30 mg kg-1) em um perfil (MI-T1) e Ba (VP >150 $\mathrm{mg} \mathrm{kg}^{-1}$ ) em um perfil (MII-T2) (Quadro 4). Portanto, esses solos construídos são enquadrados na classe 3 (Conama, 2009), o que requer controle das fontes de contaminação e monitoramento do solo e da água subterrânea. No entanto, esses dados contrastam com a reconhecida contaminação por metais gerada pela DAM (Boult et al., 1994; Salomons, 1995; Johnson e Hallberg, 2005; Akcil e Koldas, 2006), indicando que o controle da acidez pode mitigar essa contaminação em níveis aceitáveis.

\section{Análise multivariada dos componentes principais para as áreas I e II}

Os componentes principais foram extraídos a partir da decomposição do valor singular da matriz de dados para as propriedades físicas e químicas avaliadas dos solos construídos das áreas I, II, IV e VII (Quadro 5).

$\mathrm{Na}$ análise multivariada de componentes principais dos solos construídos mais antigos, pertencentes às áreas I e II, foram necessários os primeiros cinco componentes principais para explicar a máxima informação significante das propriedades do solo avaliadas neste estudo, enquanto para os solos mais jovens das áreas IV e VII foram retidos os primeiros três componentes principais (Quadro 5). A seleção dessas variáveis latentes satisfez os dois critérios mais comuns para escolha do número ótimo de componentes principais a serem retidos (Jolliffe, 2002); isto é, selecionar aqueles componentes com autovalores maiores que 1 e determinado subconjunto de componentes principais que explica no mínimo $70 \%$ da variância dos dados. O uso combinado desses critérios foi utilizado por Ramos et al. (2007), para avaliar o impacto da sistematização nas propriedades físicohídricas do solo em áreas cultivadas com videiras, e por Visconti et al. (2009), os quais aplicaram a análise de componentes principais para identificar os fatores que controlam as propriedades químicas no extrato de saturação do solo de uma área agrícola irrigada na Espanha.

$\mathrm{Na}$ análise dos componentes principais dos solos construídos mais antigos (áreas I e II), o primeiro componente principal (1 - MI e MII) explica $28,9 \%$ da variância das propriedades físicas e químicas analisadas (Quadro 5). Essa variável latente é moderada a altamente e negativamente correlacionada com $\mathrm{Ca}(\mathrm{r}=-0,66), \mathrm{Mg}(\mathrm{r}=-0,74)$, $\mathrm{V}(-0,68)$ e $\mathrm{SB}(\mathrm{r}=-0,80)$, PA $(\mathrm{r}=-0,80)$, Ba $(\mathrm{r}=-0,61)$, Co $(-0,88)$, Ni $(-0,93)$ e positivamente com PL $(r=0,80)$. As correlações negativas indicam que o primeiro componente é inversamente proporcional à variável em questão; e as positivas, proporcionalidade direta. Esse componente principal pode ser interpretado como uma nova variável, que reflete o comportamento das bases nesses solos construídos mais antigos, bem como alguns metais pesados (Figura 4a). A análise multivariada dos componentes principais tem sido usada no estudo das propriedades físicas e químicas e na distribuição de metais pesados em solos (Barona e Romero, 
Quadro 4. Potencial de acidificação (PA), potencial de neutralização (PN), potencial líquido de acidificação (PL) e metais potencialmente disponíveis extraídos pelo método USEPA 3050B, em perfis de solos construídos com diferentes idades

\begin{tabular}{|c|c|c|c|c|c|c|c|c|c|c|c|c|c|c|c|c|c|c|}
\hline $\begin{array}{l}\text { Perfil } \\
\text { (Idade) }\end{array}$ & $\mathbf{N}^{\circ}$ & Prof. $^{(1)}$ & PN & PA & PL & $\mathbf{B a}$ & Mn & $\mathbf{F e}$ & $\mathrm{Cu}$ & $\mathbf{Z n}$ & $\mathrm{Ni}$ & $\mathrm{Cr}$ & Co & $\mathbf{P b}$ & Cd & Mo & As & Se \\
\hline & & $\mathrm{m}$ & & $\mathrm{Mg}^{-1} \mathrm{C}$ & & & & & & & & $\mathrm{kg}^{-1}$ & & & & & & \\
\hline \multirow{4}{*}{$\begin{array}{l}\text { MI-T1 } \\
\text { (44 anos) }\end{array}$} & 1 & $0,00-0,10$ & $<0,01$ & 11,5 & $-11,5$ & 58 & 8 & 8671 & 17 & 20 & 7 & 18 & 7 & 26 & ${ }^{*} 0,1$ & 5,00 & 4,00 & 16 \\
\hline & 2 & $0,40-0,50$ & $<0,01$ & 12,4 & $-12,4$ & 63 & 9 & 12949 & 16 & 18 & 6 & 12 & 5 & 23 & ${ }^{*} 0,1$ & 5,00 & 7,00 & 6 \\
\hline & 3 & $1,00-1,10$ & $<0,01$ & 10,1 & $-10,1$ & 66 & 8 & 6988 & 15 & 22 & 8 & 9 & 7 & 23 & ${ }^{*} 0,1$ & 5,00 & 5,00 & 20 \\
\hline & 4 & $1,90-2,00$ & $<0,01$ & 12,2 & $-12,2$ & 53 & 11 & 7961 & 17 & 28 & 8 & 10 & 7 & 20 & ${ }^{*} 0,1$ & 33,00 & 6,00 & 9 \\
\hline \multirow{4}{*}{$\begin{array}{l}\text { MI-T2 } \\
\text { (44 anos) }\end{array}$} & 5 & $0,00-0,10$ & $<0,01$ & 10,7 & $-10,7$ & 56 & 16 & 16355 & 14 & 63 & 11 & 11 & 10 & 22 & ${ }^{*} 0,1$ & 2,00 & 16,00 & 4 \\
\hline & 6 & $0,40-0,50$ & $<0,01$ & 10,3 & $-10,3$ & 63 & 13 & 9750 & 15 & 32 & 15 & 8 & 14 & 24 & ${ }^{*} 0,1$ & 10,00 & 3,00 & 13 \\
\hline & 7 & $1,00-1,10$ & $<0,01$ & 32,5 & $-32,5$ & 57 & 13 & 11712 & 13 & 34 & 15 & 8 & 13 & 18 & ${ }^{*} 0,1$ & 3,00 & 21,00 & 17 \\
\hline & 8 & $1,90-2,00$ & $<0,01$ & 9,1 & $-9,1$ & 60 & 10 & 7250 & 11 & 22 & 11 & 8 & 9 & 20 & ${ }^{*} 0,1$ & 3,00 & 5,00 & 11 \\
\hline \multirow{4}{*}{$\begin{array}{l}\text { MI-T3 } \\
\text { (44 anos) }\end{array}$} & 9 & $0,00-0,10$ & $<0,01$ & 5,6 & $-5,6$ & 55 & 28 & 14039 & 55 & 11 & 3 & 12 & 4 & 23 & ${ }^{*} 0,1$ & 1,00 & 3,00 & 13 \\
\hline & 10 & $0,40-0,50$ & $<0,01$ & 5,4 & $-5,4$ & 46 & 10 & 11173 & 10 & 11 & 3 & 10 & 3 & 18 & ${ }^{*} 0,1$ & 5,00 & 11,00 & $* 1$ \\
\hline & 11 & $1,00-1,10$ & $<0,01$ & 9,0 & $-9,0$ & 45 & 11 & 13700 & 11 & 10 & 3 & 9 & 5 & 22 & ${ }^{*} 0,1$ & 2,00 & 16,00 & 9 \\
\hline & 12 & $1,90-2,00$ & $<0,01$ & 6,6 & $-6,6$ & 51 & 10 & 10375 & 8 & 9 & 3 & 9 & 2 & 18 & ${ }^{*} 0,1$ & 4,00 & 19,00 & 2 \\
\hline \multirow{4}{*}{$\begin{array}{l}\text { MII-T1 } \\
\text { (28 anos) }\end{array}$} & 13 & $0,00-0,10$ & $<0,01$ & 13,1 & $-13,1$ & 124 & 12 & 6848 & 9 & 9 & 6 & 9 & 6 & 17 & ${ }^{*} 0,1$ & 5,00 & 8,00 & 17 \\
\hline & 14 & $0,40-0,50$ & $<0,01$ & 20,7 & $-20,7$ & 89 & 15 & 5481 & 14 & 11 & 10 & 8 & 8 & 18 & ${ }^{*} 0,1$ & 4,00 & 15,00 & 3 \\
\hline & 15 & $1,00-1,10$ & $<0,01$ & 19,8 & $-19,8$ & 71 & 18 & 5648 & 8 & 12 & 11 & 6 & 9 & 18 & ${ }^{*} 0,1$ & 4,00 & 2,00 & 22 \\
\hline & 16 & $1,90-2,00$ & $<0,01$ & 26,9 & $-26,9$ & 94 & 24 & 4705 & 8 & 16 & 15 & 7 & 14 & 13 & ${ }^{*} 0,1$ & 2,00 & 12,00 & 9 \\
\hline \multirow{4}{*}{$\begin{array}{l}\text { MII-T2 } \\
\text { (25 anos) }\end{array}$} & 17 & $0,00-0,10$ & $<0,01$ & 10,3 & $-10,3$ & 73 & 15 & 7480 & 9 & 23 & 5 & 7 & 5 & 15 & ${ }^{*} 0,1$ & 4,00 & 22,00 & 4 \\
\hline & 18 & $0,40-0,50$ & $<0,01$ & 10,1 & $-10,1$ & 69 & 34 & 11225 & 10 & 17 & 6 & 7 & 6 & 18 & ${ }^{*} 0,1$ & 2,00 & ${ }^{*} 0,15$ & 13 \\
\hline & 19 & $1,00-1,10$ & $<0,01$ & 8,6 & $-8,6$ & 96 & 33 & 10287 & 11 & 22 & 10 & 8 & 9 & 21 & ${ }^{*} 0,1$ & 3,00 & 11,00 & 16 \\
\hline & 20 & $1,90-2,00$ & $<0,01$ & 28,7 & $-28,7$ & 237 & 90 & 7139 & 12 & 22 & 16 & 7 & 12 & 16 & ${ }^{*} 0,1$ & 2,00 & 5,00 & 14 \\
\hline \multirow{4}{*}{$\begin{array}{l}\text { MII-T3 } \\
\text { (19 anos) }\end{array}$} & 21 & $0,00-0,10$ & $<0,01$ & 8,9 & $-8,9$ & 57 & 15 & 8637 & 22 & 37 & 6 & 7 & 5 & 24 & ${ }^{*} 0,1$ & 3,00 & ${ }^{*} 0,15$ & 2 \\
\hline & 22 & $0,40-0,50$ & $<0,01$ & 11,0 & $-11,0$ & 77 & 12 & 7455 & 21 & 38 & 7 & 7 & 7 & 21 & ${ }^{*} 0,1$ & ${ }^{*} 0,10$ & ${ }^{*} 0,15$ & $* 1$ \\
\hline & 23 & $1,00-1,10$ & $<0,01$ & 8,2 & $-8,2$ & 56 & 12 & 6674 & 21 & 39 & 9 & 8 & 6 & 18 & ${ }^{*} 0,1$ & 1,00 & 3,00 & $* 1$ \\
\hline & 24 & $1,90-2,00$ & $<0,01$ & 8,7 & $-8,7$ & 48 & 14 & 5628 & 22 & 40 & 10 & 6 & 8 & 14 & ${ }^{*} 0,1$ & 1,00 & 8,00 & $* 1$ \\
\hline \multirow{4}{*}{$\begin{array}{l}\text { MIV-T1 } \\
\text { (18 anos) }\end{array}$} & 1 & $0,00-0,10$ & 1,03 & 0,6 & 0,4 & 88 & 112 & 14224 & 18 & 19 & 4 & 19 & 4 & 18 & ${ }^{*} 0,1$ & 1,00 & 5,00 & *1 \\
\hline & 2 & $0,60-0,70$ & $<0,01$ & 6,2 & $-6,2$ & 64 & 38 & 8065 & 19 & 24 & 9 & 11 & 6 & 24 & ${ }^{*} 0,1$ & 1,00 & 5,00 & $* 1$ \\
\hline & 3 & $1,00-1,10$ & 4,72 & 6,6 & $-1,8$ & 63 & 184 & 7595 & 24 & 33 & 18 & 5 & 8 & 21 & ${ }^{*} 0,1$ & ${ }^{*} 0,10$ & 14,00 & $* 1$ \\
\hline & 4 & $1,90-2,00$ & 6,33 & 7,2 & $-0,9$ & 58 & 266 & 8130 & 16 & 213 & 22 & 6 & 10 & 21 & ${ }^{*} 0,1$ & 2,00 & 30,00 & $* 1$ \\
\hline \multirow{4}{*}{$\begin{array}{l}\text { MIV-T2 } \\
\text { (17 anos) }\end{array}$} & 5 & $0,00-0,10$ & 2,57 & 0,3 & 2,3 & 51 & 166 & 14244 & 14 & 21 & 4 & 24 & 4 & 18 & ${ }^{*} 0,1$ & ${ }^{*} 0,10$ & 1,00 & $* 1$ \\
\hline & 6 & $0,60-0,70$ & $<0,01$ & 0,6 & $-0,6$ & 66 & 54 & 16341 & 17 & 16 & 4 & 40 & 3 & 19 & ${ }^{*} 0,1$ & 2,00 & 16,00 & *1 \\
\hline & 7 & $1,00-1,10$ & 1,06 & 10,4 & $-9,3$ & 82 & 67 & 8465 & 39 & 36 & 11 & 8 & 8 & 23 & ${ }^{*} 0,1$ & 1,00 & 6,00 & $* 1$ \\
\hline & 8 & $1,90-2,00$ & $<0,01$ & 7,8 & $-7,8$ & 45 & 103 & 7225 & 18 & 37 & 14 & 9 & 9 & 16 & ${ }^{*} 0,1$ & 2,00 & 18,00 & $* 1$ \\
\hline \multirow{4}{*}{$\begin{array}{l}\text { MVII-T3 } \\
\text { (10 anos) }\end{array}$} & 9 & $0,00-0,10$ & 7,27 & 0,9 & 6,3 & 74 & 104 & 18474 & 14 & 13 & 3 & 21 & 4 & 21 & ${ }^{*} 0,1$ & 2,00 & 1,00 & $* 1$ \\
\hline & 10 & $0,60-0,70$ & 2,09 & 5,3 & $-3,2$ & 52 & 58 & 8371 & 16 & 32 & 11 & 7 & 8 & 20 & ${ }^{*} 0,1$ & 1,00 & 18,00 & $* 1$ \\
\hline & 11 & $1,00-1,10$ & 6,30 & 5,9 & 0,4 & 80 & 58 & 6867 & 18 & 42 & 17 & 8 & 12 & 22 & ${ }^{*} 0,1$ & 1,00 & 9,00 & $* 1$ \\
\hline & 12 & $1,90-2,00$ & 4,71 & 10,0 & $-5,3$ & 52 & 55 & 5951 & 18 & 37 & 16 & 6 & 12 & 22 & ${ }^{*} 0,1$ & 1,00 & 30,00 & $* 1$ \\
\hline \multirow{4}{*}{$\begin{array}{l}\text { MIV-T4 } \\
\text { (4 anos) }\end{array}$} & 13 & $0,00-0,10$ & 7,77 & 0,6 & 7,2 & 90 & 226 & 16140 & 28 & 16 & 4 & 15 & 6 & 16 & ${ }^{*} 0,1$ & 2,00 & 1,00 & *1 \\
\hline & 14 & $0,60-0,70$ & 5,75 & 0,6 & 5,1 & 60 & 54 & 22372 & 13 & 22 & 4 & 14 & 7 & 16 & ${ }^{*} 0,1$ & 1,00 & ${ }^{*} 0,15$ & *1 \\
\hline & 15 & $1,00-1,10$ & $<0,01$ & 8,6 & $-8,6$ & 45 & 93 & 8626 & 18 & 61 & 15 & 7 & 12 & 21 & ${ }^{*} 0,1$ & 3,00 & 12,00 & $* 1$ \\
\hline & 16 & $1,90-2,00$ & 1,06 & 5,1 & $-4,0$ & 34 & 241 & 16527 & 18 & 37 & 20 & 5 & 11 & 22 & ${ }^{*} 0,1$ & ${ }^{*} 0,10$ & ${ }^{*} 0,15$ & $* 1$ \\
\hline
\end{tabular}

(1) Prof.: profundidade da camada de solo; * Valor referente ao limite de detecção do equipamento utilizado para leitura da amostra. Valores de prevenção $\left(\mathrm{mg} \mathrm{kg}^{-1}\right): \mathrm{As}=15,0 ; \mathrm{Ba}=150,0 ; \mathrm{Cd}=1,3 ; \mathrm{Pb}=72,0 ; \mathrm{Co}=25,0 ; \mathrm{Cu}=60,0 ; \mathrm{Cr}=75,0 ; \mathrm{Mo}=30,0 ; \mathrm{Ni}=30,0$; $\mathrm{Se}=5,0 ; \mathrm{e} \mathrm{Zn}=300,0$. Valores de investigação $\left(\mathrm{mg} \mathrm{kg}^{-1}\right)$ : $\mathrm{As}=35,0 ; \mathrm{Ba}=300,0 ; \mathrm{Cd}=3,0 ; \mathrm{Pb}=180,0 ; \mathrm{Co}=35,0 ; \mathrm{Cu}=200,0 ; \mathrm{Cr}=150,0 ;$ $\mathrm{Mo}=50,0 ; \mathrm{Ní}=70,0 ; \mathrm{Se}=5,0 ; \mathrm{e} \mathrm{Zn}=450,0$ (Conama, 2009). 
Quadro 5. Resultados da análise dos componentes principais para os solos construídos mais antigos localizados nas áreas I e II e para aqueles mais jovens pertencentes às áreas IV e VII

\begin{tabular}{lccc}
\hline \multirow{2}{*}{$\begin{array}{l}\text { Componente } \\
\text { principal }\end{array}$} & \multirow{2}{*}{ Autovalor } & \multicolumn{2}{c}{ Variância } \\
\cline { 3 - 4 } & & \multicolumn{2}{c}{$\%$} \\
\cline { 3 - 4 } 1- MI e MII & 2,893 & 28,9 & 28,9 \\
2 - MI e MII & 2,384 & 19,6 & 48,5 \\
3 - MI e MII & 1,756 & 10,6 & 59,1 \\
4 - MI e MII & 1,645 & 9,3 & 68,4 \\
5 - MI e MII & 1,344 & 6,2 & 74,6 \\
1- MIV e MVII & 3,609 & 44,9 & 44,9 \\
2- MIV e MVII & 2,492 & 21,4 & 66,3 \\
3- MIV e MVII & 1,537 & 8,2 & 74,5 \\
\hline
\end{tabular}

1 - MI e MII; 2 - MI e MII; 3 - MI e MII; 4 - MI e MII; e 5 - MI e MII: componentes principais $1,2,3,4$ e 5 , respectivamente, dos solos construídos das áreas I e II; 1 - MIV e MVII; 2 - MIV e MVII; e 3 - MIV e MVII: componentes principais 1, 2, 3, respectivamente, dos solos construídos das áreas IV e VII.
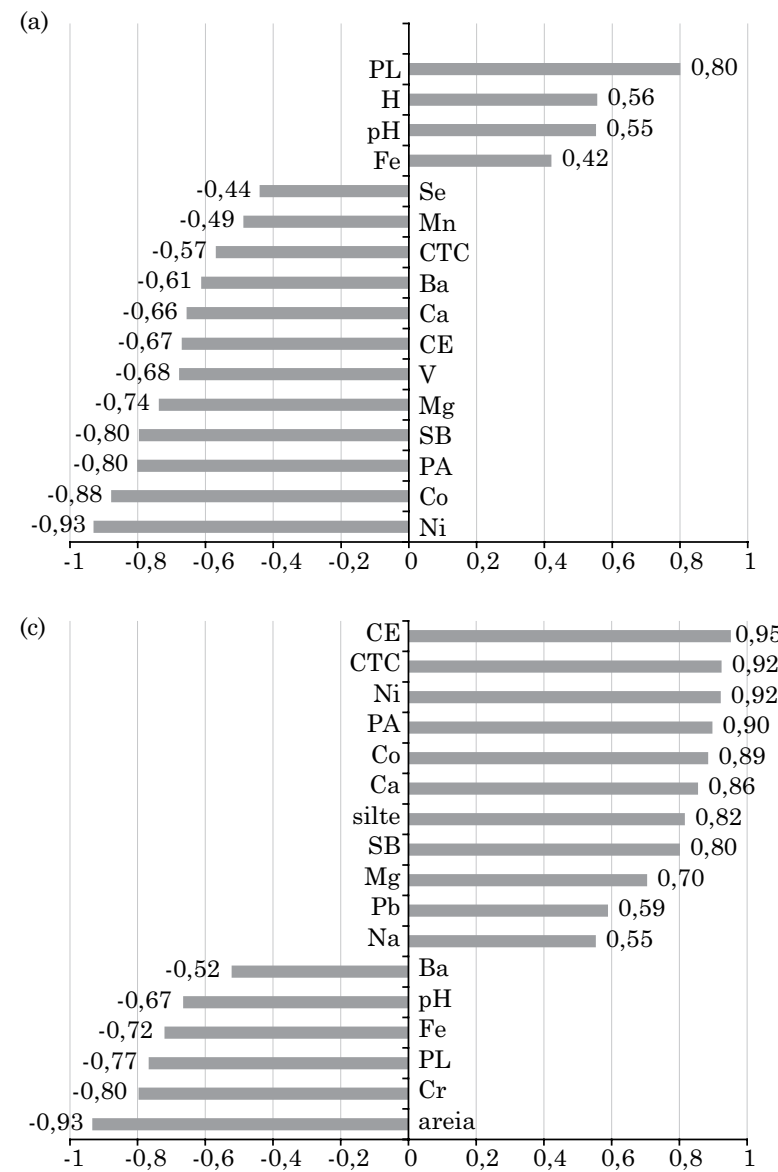

1996; Fadigas et al., 2002; Gomes et al., 2004; Boruvka et al., 2005; Guedes et al., 2006).

O segundo componente principal (2 - MI e MII), explica 19,6 \% da variância das propriedades do solo avaliadas (Quadro 5), é moderadamente a altamente correlacionado com $\mathrm{Ca}(\mathrm{r}=0,50), \mathrm{K}$ $(\mathrm{r}=0,81), \mathrm{V}(\mathrm{r}=0,59), \mathrm{pH}(\mathrm{r}=0,68)$ e $\mathrm{Al}(\mathrm{r}=-0,80)$. As correlações positivas e negativas entre essas propriedades do solo construído e a variável latente 2 - MI e MII (Figura 4b) apresentam coerência, pois à medida que $\mathrm{Ca}, \mathrm{K}, \mathrm{V}$ e $\mathrm{pH}$ aumentam há a tendência do deslocamento no equilíbrio ácido-base para a faixa mais básica, com consequente decréscimo na concentração de Al. Portanto, o segundo componente principal pode ser interpretado como a acidez dos solos construídos.

Os biplots relativos aos dois primeiros componentes principais das análises multivariadas realizadas nos solos construídos das áreas I, II, IV e VII são apresentados na Figura 5. O biplot é a representação gráfica de uma matriz de dados multivariada, contendo observações e
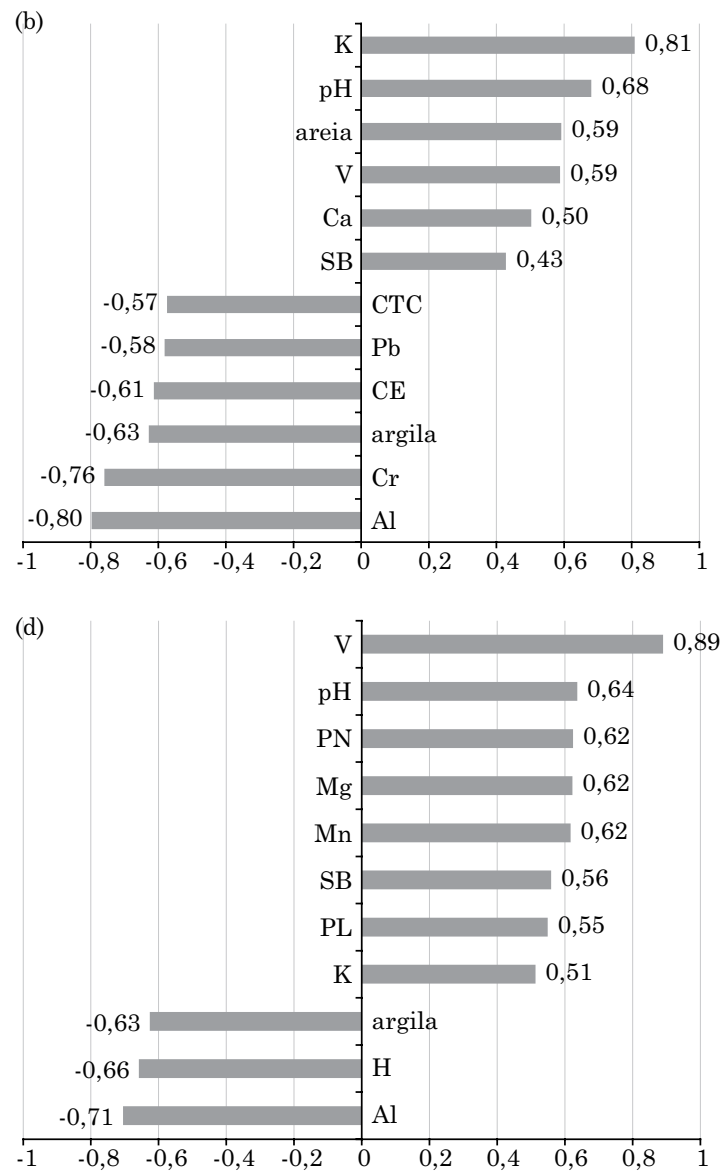

Figura 4. Coeficientes de correlação de Pearson. (a) e (b) correlações do primeiro e segundo componente principal com as propriedades do solo construído nas áreas I e II, respectivamente; e (c) e (d) correlações do primeiro e segundo componente principal com as propriedades do solo construído nas áreas IV e VII, respectivamente. As correlações exibidas foram significativas a $5 \%$. 
variáveis (Everitt e Hothorn, 2011), e com base na decomposição do valor singular de uma matriz (Gabriel, 1971).

No biplot dos componentes principais dos solos construídos das áreas I e II (Figura 5a), com base no eixo horizontal (primeiro componente principal), observaram-se altas correlações entre $\mathrm{Ba}, \mathrm{Ni}$ e Co com $\mathrm{Mg}$ e PA, ambas variáveis com variâncias semelhantes, além de um grupo de amostras representando camadas de solo construído $\left(\mathrm{n}^{\circ} 7\right.$, 15 e 16), que são mais similares em relação aos valores dessas variáveis, indicando valores elevados (Quadros 2 e 4). Correlações altas também foram observadas entre $\mathrm{Ca}, \mathrm{Na}, \mathrm{V}, \mathrm{SB}, \mathrm{Mn}$ e $\mathrm{Zn}$ com menores variâncias para $\mathrm{Na}$ e $\mathrm{Zn}$. Em relação a esse grupo de variáveis, a amostra de solo $\mathrm{n}^{\circ} 20$ (MII T2, profundidade 1,90 a 2,00 m - Quadros 2 e 4) foi a que exibiu os maiores valores de $\mathrm{Ca}, \mathrm{SB}$ e $\mathrm{Mn}$ (Figura 5a). Correlações igualmente altas também ocorreram entre as variáveis $\mathrm{PL}, \mathrm{Cu}, \mathrm{Fe}$ e $\mathrm{H}$, observando-se ainda a formação de um grupo de amostras de solo ( ${ }^{\circ} 9$ a 12$)$ próximo à extremidade do vetor da variável PL (Figura 5a), que representa o perfil completo da área MI T3. Isso indica os menores valores do potencial líquido em profundidade ao longo de todo perfil desse solo construído, exibindo assim uma tendência mais fraca de acidificação dessas camadas, em relação aos perfis das áreas I e II (Quadro 4).

$\mathrm{O}$ segundo componente principal diferenciou as variáveis químicas relacionadas à acidez dos solos construídos das áreas I e II. Observaram-se correlações semelhantes entre $\mathrm{pH}, \mathrm{K}, \mathrm{CTC}, \mathrm{CE}$ e Al, com altas correlações negativas entre esses grupos constituídos de duas e três variáveis, respectivamente, apresentando ainda variância semelhante (Figura 5a). A alta correlação entre CTC e CE, indicada pelo biplot, caracteriza o processo de sulfurização ativa nesses solos construídos, pois nessa situação observam-se valores elevados para essas propriedades químicas, com os maiores valores para soma de bases e acidez potencial (Inda et al., 2010). Alta correlação entre os metais pesados $\mathrm{Pb}$ e Cr foram observadas, com seus maiores teores encontrados na amostra $n^{\circ} 1$, que representa a camada de 0,00-0,10 m de MI TI; essa camada também exibiu os maiores valores para argila, $\mathrm{Al}$ e CTC (Quadro 2).

\section{Análise multivariada dos componentes principais para as áreas IV e VII}

Na segunda análise multivariada dos componentes principais realizada nos solos construídos das áreas IV e VII, houve menor distribuição da variância entre os componentes principais, necessitando dessa forma da retenção de um número menor de variáveis latentes para atender o critério de Jolliffe (2002). Isso provavelmente ocorreu em razão da similaridade das propriedades físicas e químicas entre as camadas
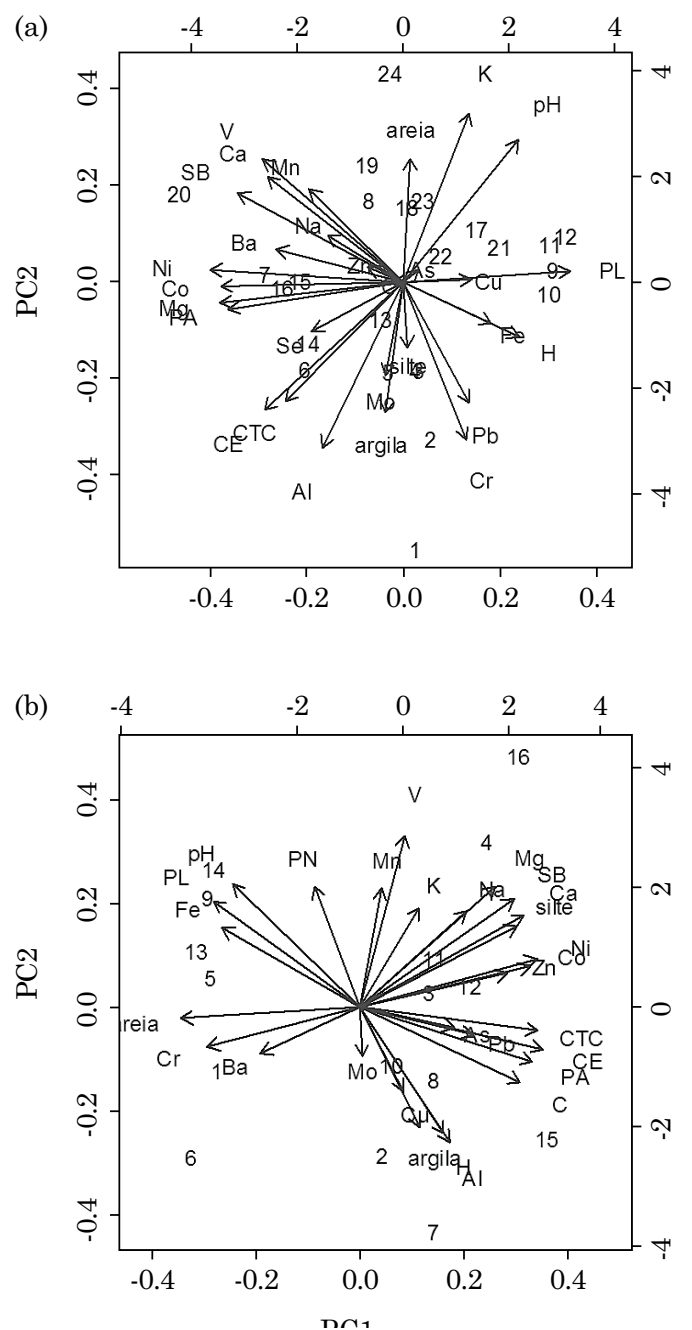

Figura 5. Biplots dos primeiros dois componentes principais obtidos das análises multivariadas. (a) e (b) Biplots referentes à análise de componentes principais dos solos construídos das áreas I, II, IV e VII, respectivamente.

superficiais de topsoil e argila e do estéril de mineração. O primeiro componente principal (1- MIV e MVII) explica 44,9 \% da variância das propriedades físicas e químicas analisadas (Quadro 5). Esse componente é altamente correlacionado com PA $(\mathrm{r}=0,90)$, CTC $(r=0,92)$ e CE $(r=0,95)$; com Na $(\mathrm{r}=0,55), \mathrm{Mg}(\mathrm{r}=0,70), \mathrm{Ca}(\mathrm{r}=0,86)$; com $\mathrm{Pb}$ $(\mathrm{r}=0,59), \mathrm{Co}(\mathrm{r}=0,89), \mathrm{Ni}(0,92), \mathrm{Cr}(\mathrm{r}=-0,80)$ e $\mathrm{Fe}$ $(-0,72)$. Portanto, essa variável latente representa o processo de sulfurização associado às bases e aos metais pesados desses solos construídos (Figura 4c). O segundo componente principal (2 - MIV e MVII) explica 21,4 \% da variância das propriedades avaliadas (Quadro 5), possuindo alta correlação com $\mathrm{PN}(\mathrm{r}=0,62), \mathrm{pH}(\mathrm{r}=0,64), \mathrm{V}(\mathrm{r}=0,89)$ e $\mathrm{Al}(\mathrm{r}=-0,71)$. Dessa forma, pode ser interpretado como as bases presentes nos solos construídos.

Analisando o biplot dos componentes principais para os solos construídos das áreas IV e VII 
(Figura 5b), de acordo com o eixo referente ao primeiro componente, observaram-se algumas diferenças em relação ao biplot para os solos das áreas I e II; isto é, houve maior agrupamento dos cátions básicos (Ca, Mg, Na e K), com correlações elevadas e variância semelhantes. Além disso, constatou-se a existência de um padrão de distribuição dos metais pesados diferente, bem como maior correlação entre as propriedades químicas ligadas à acidez desses solos construídos. Essas diferenças são em razão das camadas de topsoil e argila, que não sofrem interferência pela oxidação da pirita.

$\mathrm{A}$ areia e os elementos $\mathrm{Cr}$ e $\mathrm{Ba}$ apresentaram altas correlações e variâncias semelhantes, o mesmo ocorreu com $\mathrm{Ni}$, Co e Zn, onde as amostras n 3 e 12 (MIV TI 1,00-1,10 m e MVII T3 1,90-2,00 m), que correspondem a solos construídos com 18 e 10 anos, respectivamente, apresentaram teores médios desses metais pesados (Quadro 4). Cálcio, $\mathrm{Mg}$ e $\mathrm{Na}$ evidenciaram alta correlação com a SB além de variâncias semelhantes; o $\mathrm{Ca}$ e $\mathrm{Mg}$, por possuírem maior concentração ao longo de todo o perfil desses solos construídos, contribuem mais para a SB (Quadro 2). As variáveis $\mathrm{pH}$ e PL possuem alta correlação e variâncias muito semelhantes (Figura 5b); as amostras $n^{\circ} 9$ (terra vegetal) e 14 (argila), que correspondem a MVI T3 0,00-0,10 m e MIV T4 0,70-0,80 m, respectivamente, possuem os maiores valores dessas variáveis (Quadro 2), caracterizando condição mais adequada para o crescimento e desenvolvimento de plantas sob o ponto de vista químico.

$\mathrm{O}$ pH e PL possuem alta correlação negativa com o potencial de acidificação (PA), As, $\mathrm{Pb}, \mathrm{CE}$ e CTC. $\mathrm{O}$ relacionamento entre esse grupo de variáveis evidencia um processo de sulfurização ativa, em que na ausência de carbonatos ( $\mathrm{PN}$ nulo) o $\mathrm{pH}$ pode ser inferior a 3,5 (Pinto, 1997), correspondendo a um PL mais negativo. Nessa condição, ocorre maior dissolução dos minerais do solo, em razão do ácido sulfúrico produzido pela oxidação dos sulfetos, e liberação de metais pesados, levando à formação de sais e elevação da condutividade elétrica da solução. O comportamento de metais pesados por causa do pH é amplamente conhecido na literatura científica; no caso do $\mathrm{Pb}$, sua disponibilidade diminui com a aplicação de calagem em razão da precipitação na forma de hidróxidos, fosfatos, carbonatos ou na forma de complexos orgânicos bastante estáveis; para o As, suas formas mais móveis no ambiente $\left(\mathrm{AsO}_{2}^{-}, \mathrm{AsO}_{4}^{3 \text {; }}\right.$ $\mathrm{HAsO}_{4}^{2-}$ e $\left.\mathrm{H}_{2} \mathrm{AsO}_{4}^{-}\right)$são sorvidas preferencialmente na faixa de $\mathrm{pH}$ entre 7 e 9 (Kabata-Pendias, 2011).

$\mathrm{O}$ segundo componente principal indicou alta correlação negativa entre $\mathrm{PN}$ e $\mathrm{H}, \mathrm{Al}, \mathrm{Cu}$, Mo e argila; esse último grupo de variáveis apresentou alta correlação entre si (Figura 5b). O comportamento entre essas variáveis indica que os solos construídos com maior potencial de neutralização possuem menores teores de $\mathrm{H}$ e $\mathrm{Al}$ e de $\mathrm{Cu}$ e $\mathrm{Mo}$.
Dessa forma, a análise multivariada de componentes principais foi capaz de discriminar quais propriedades físicas e, ou, químicas, avaliadas neste estudo, apresentaram maior importância em relação ao processo de sulfurização atualmente vigente nas áreas mineradas, bem como possibilitou identificar as camadas de solos que evidenciaram maiores ou menores valores de metais pesados, que influenciaram na contaminação dos perfis de solos construídos, caracterizando o processo de geração de drenagem ácida de modo mais detalhado em relação a uma análise estatística univariada.

\section{CONCLUSÕES}

Os solos construídos das áreas mais antigas evidenciam uma condição extrema de acidificação ao longo de todo o perfil, com pHs abaixo de 3,2 , e o complexo trocável praticamente saturado com alumínio, apresentando ainda os potenciais de acidificação mais elevados, o que indica a fase catalítica do estádio de sulfurização ativa e a continuidade de atuação do processo ao longo do tempo.

A colocação de topsoil e argila para recuperar os solos construídos das áreas mais jovens, apesar de proporcionar condições químicas favoráveis ao estabelecimento de culturas agrícolas na superfície, não evita a formação de drenagem ácida em profundidade.

A acidificação em profundidade nos solos construídos mais jovens é menos intensa do que nos solos mais antigos, com presença de potencial de neutralização, maiores valores de $\mathrm{pHs}$ e cátions básicos e menores potenciais de acidificação, provavelmente em razão de diferenças no material geológico componente dos estéreis.

O processo de sulfurização e sua relação com a liberação de metais foi mais bem caracterizado pela análise de componentes principais realizada nas áreas IV e VII, em razão de a correlação entre $\mathrm{pH}$ e saturação por bases nos estéreis só se expressar em saturações por bases acima de $40 \%$, não observada nos materiais dos estéreis das áreas I e II.

A extração dos metais pelo método USEPA 3050B demonstrou que os materiais geológicos do estéril não possuem teores naturais elevados de metais pesados, ou seja, a contaminação somente acontece por causa da geração de drenagem ácida.

\section{AGRADECIMENTOS}

Ao CNPq/Rede do Carvão, pela concessão de bolsa ao primeiro autor. À CRM, pelo apoio técnico. 


\section{REFERÊNCIAS}

Akcil A, Koldas, S. Acid Mine Drainage (AMD): causes, treatment and case studies. J Clean Prod. 2006;14:1139-45.

Barnhisel RI, Powell JL, Akin GW, Ebelhar MW. Characteristics and reclamation of "acid sulfate" mine spoils. In: Kittrick JA, Fanning DS, Hossner LR, editors. Acid sulfate weathering. Madison: Soil Science Society of America; 1982. p.225-34.

Barona A, Romero F. Distribution of metals in soils and relationships among fractions by principal component analysis. Soil Technol. 1996;8:303-19.

Boruvka L, Vacek O, Jehlicka J. Principal component analysis as a tool to indicate the origin of potentially toxic elements in soils. Geoderma. 2005;128:289-300.

Boult S, Collins DN, White KN, Curtis CD. Metal transport in a stream polluted by acid mine drainage - the AfonGouch, Anglesey, UK. Environ Pollut. 1994;84:279-84.

Campos ML, Almeida JA, Souza LS. Avaliação de três áreas de solo construído após mineração de carvão a céu aberto em Lauro Müller, Santa Catarina. R Bras Ci Solo. 2003;27:1123-37.

Conselho Nacional do Meio Ambiente - Conama. Resolução $\mathrm{n}^{\circ} 420$, de 28 de dez. 2009 [acessado em 12 dez. 2012]. Disponível em: http://www.mma.gov.br/port/conama/index.cfm.

Departamento Nacional de Produção Mineral - DNPM. Anuário mineral brasileiro, 2005 (ano base de 2004). [Acessado em 6 nov. 2012]. Disponível em: http://www.dnpm.gov.br.

Empresa Brasileira de Pesquisa Agropecuária - Embrapa. Centro Nacional de Pesquisa de Solos. Manual de métodos de análise de solo. 2a . ed. Rio de Janeiro: Embrapa Solos; 2011.

Everitt B, Hothorn T. An introduction to applied multivariate analysis with R. New York: Springer; 2011.

Fadigas FS, Amaral Sobrinho NMB, Mazur N, Anjos LHC, Freixo AA. Concentrações naturais de metais pesado sem algumas classes de solos brasileiros. Bragantia. 2002;2:151-9.

Farias CEG. Mineração e Meio Ambiente no Brasil. 2002. [acessado em 7 out. 2012]. Disponível em: http://www.mma.gov. br/estruturas/sqa_pnla/_arquivos/minera.pdf.

Gabriel KR. The biplot graphic display of matrices with application to principal component analysis. Biometrika. 1971;58:453-67.

Gomes JBV, Curi N, Motta PEF, Ker JC, Marques JJGSM, Schulze DG. Análise de componentes principais de atributos físicos, químicos e mineralógicos de solos do Bioma Cerrado. $\mathrm{R}$ Bras Ci Solo. 2004;28:137-53.

Guebert MD, Gardner TW. Macropore flow on a reclaimed surface mine: Infiltration and hillslope hydrology. Geomorphology. 2001;39:151-69.

Guedes MC, Andrade CA, Poggiani F, Mattiazzo ME. Propriedades químicas do solo e nutrição do eucalipto em função da aplicação de lodo de esgoto. R Bras Ci Solo. 2006;30:267-80.

Inda AV, Quinõnes ORG, Giasson E, Bissani CA, Dick DP, Nascimento PC. Atributos químicos relacionados ao processo de sulfurização em solos construídos após mineração de carvão. Ci Rural. 2010;40:1060-7.

Instituto Brasileiro de Geografia e Estatística - IBGE. Levantamento de recursos naturais. Folha SH 22, Porto Alegre e parte das folhas SH 21 e SI 22 Lagoa Mirim. Rio de Janeiro: 1986.

Johnson DB, Hallberg KB. Acid mine drainage remediation options: a review. Sci Total Environ. 2005;338:3-14.

Jolliffe IT. Principal component analysis. 2nd. ed. New York: Springer; 2002.

Kabata-Pendias A. Trace elements in soils and plants. 4th. ed. Boca Raton: CRC; 2011.

Kämpf N, Schneider P, Giasson, E. Propriedades, pedogênese e classificação de solos construídos em áreas de mineração na bacia carboníferado baixo Jacuí (RS). R Bras Ci Solo. 1997;21:79-88.

Massey FJ. The Kolmogorov-Smirnov test for goodness-of-fit. J Am Stat Assoc. 1951;46:68-78.

O'shay T, Hossner LR, Dixon JB. A modified hydrogen peroxide oxidation method for determination of potential acidity in pyritic overburden. J Environ Qual. 1990;19:778-82.

Pinto LFS, Kämpf N. Contaminação dos solos construídos. In: Teixeira EC, Pires MJR, editores. Meio ambiente e carvão. Impactos da exploração e utilização. Porto Alegre: FINEP/CAPES/PADCT/GTM/PUCRS/UFSC/FEPAM; 2002. p.69-92.

Pinto LFS. Potencial de acidificação e de neutralização dos materiais geológicos para a composição de solo construído em área de mineração de carvão [tese]. Porto Alegre: Universidade Federal do Rio Grande do Sul; 1997.

Ramos MC, Cots-Folch R, Martínez-Casasnovas JA. Effects of land terracing on soil properties in the Priorat region in Northeastern Spain: a multivariate analysis. Geoderma. 2007;142:251-61.

Salomons W. Environmental impact of metals derived from mining activities: processes, predictions, prevention. J Geochem Explor. 1995;52:5-23.

Singer PC, Stumm W. Acid mine drainage: the rate-determining step. Science. 1970;167:1121-3.

Tedesco MJ, Gianello G, Bissani CA, Bohnen H, Volkweiss SJ. Análises de solo, plantas e outros materiais. $2^{\text {a }}$. ed. Porto Alegre: Universidade Federal do Rio Grande do Sul; 1995. (Boletim técnico, 5).

United States of Environmental Protection Agency - USEPA. Method 3050 B. 1998 [acessado em 12 fev. 2012]. Disponível em: http://www.epa.gov/SW-46/pdfs/3050b.pdf.

Visconti F, De Paz JM, Rubio JL. Principal component analysis of chemical properties of soil saturation extracts from an irrigated Mediterranean area: implications for calcite equilibrium in soil solutions. Geoderma. 2009;151:407-16.

Wilding LP, Drees LR. Spatial variability and pedology. Dev Soil Sci. 1983;11:83-116.

Zanella R. Investigação dos problemas ambientais relacionados com a exploração intensiva e queima de carvão termoelétrico em Candiota (RS) [dissertação]. Santa Maria: Universidade Federal de Santa Maria; 1988. 